\title{
Precipitation over Northern South America and Its Seasonal Variability as Simulated by the CMIP5 Models
}

\author{
Juan P. Sierra, Paola A. Arias, and Sara C. Vieira \\ Grupo de Ingeniería y Gestión Ambiental (GIGA), Escuela Ambiental, Facultad de Ingeniería, \\ Universidad de Antioquia, Medellín, Colombia \\ Correspondence should be addressed to Juan P. Sierra; pablo.sierra@udea.edu.co
}

Received 11 July 2014; Revised 13 November 2014; Accepted 20 November 2014

Academic Editor: Hann-Ming H. Juang

Copyright (C) 2015 Juan P. Sierra et al. This is an open access article distributed under the Creative Commons Attribution License, which permits unrestricted use, distribution, and reproduction in any medium, provided the original work is properly cited.

\begin{abstract}
Northern South America is identified as one of the most vulnerable regions to be affected by climate change. Furthermore, recent extreme wet seasons over the region have induced socioeconomic impacts of wide proportions. Hence, the evaluation of rainfall simulations at seasonal and interannual time scales by the CMIP5 models is urgently required. Here, we evaluated the ability of seven CMIP5 models (selected based on literature review) to represent the seasonal mean precipitation and its interannual variability over northern South America. Our results suggest that it is easier for models to reproduce rainfall distribution during boreal summer and fall over both oceans and land. This is probably due to the fact that during these seasons, incoming radiation and ocean-atmosphere feedbacks over Atlantic and Pacific oceans locate the ITCZ on the Northern Hemisphere, as suggested by previous studies. Models exhibit the worse simulations during boreal winter and spring, when these processes have opposite effects locating the ITCZ. Our results suggest that the models with a better representation of the oceanic ITCZ and the local low-level jets over northern South America, such as the Choco low-level jet, are able to realistically simulate the main features of seasonal precipitation pattern over northern South America.
\end{abstract}

\section{Introduction}

From the standpoint of atmospheric dynamics, northern South America is a complex region, due to the interaction between several atmospheric phenomena and local surface conditions (like topography, vegetation, and land use), generating a rainfall distribution that varies in wide temporal and spatial ranges. The annual cycle of precipitation over this region is controlled by the meridional migration of the Intertropical Convergence Zone (ITCZ) [1] that follows the seasonal movement of insolation, producing bimodal or unimodal precipitation patterns over specific regions in northern South America ([1], and references therein). However, the annual cycle of precipitation over northern South America is not completely explained by the ITCZ excursions. The existence of regional processes, like the presence of several low-level jets, strongly influences the amounts of precipitation over the region, defining local rainfall patterns. Particularly, the Choco low-level jet, located at near-surface levels $(925 \mathrm{hPa})$ about $5^{\circ} \mathrm{N}$, induces transport of large quantities of moisture to the continent, explaining the existence of one of the rainiest places in the world [2]. Other local low-level jets influencing precipitation in this area are the Caribbean low-level jet (CLLJ) [3] and the Equatorial Midtropospheric Easterly Jet (EMEJ) [4]. The former is located at surface levels around $10-12^{\circ} \mathrm{N}$ and its magnitude varies semiannually [3]. During the months of December-February (DJF), one of the branches of the CLLJ veers toward the eastern Pacific, merging with the Choco jet, intensifying moisture transport and convection over the region [2]. In addition, this jet has potential effects on tropical convective systems and transports large amounts of moisture from the tropical Atlantic into the Caribbean Sea and the Eastern Pacific [3]. On the other hand, the EMEJ is located around $700-600 \mathrm{hPa}$ over the Equator, showing a pronounced annual cycle [1] and interacting with the Choco jet, which strengthens deep convection over western and central Colombia [2]. Both the meridional position of the ITCZ and the activity of low-level jets like the Choco jet induce the formation of Mesoscale Convective Systems [5], which also influences the annual cycle of precipitation over the region [1]. 
Another moisture source for northern South America is the water vapor advected from the Atlantic Ocean by the action of the easterly winds that flow throughout this ocean [6]. Once entering over South America, these winds follow the orographic barrier imposed by the Andes, developing the South American low-level jet (SALLJ) [7]. This jet carries an important amount of water vapor, contributing to the atmospheric moisture over the Amazon and, consequently, to the high percentages of recycled precipitation over the region [7]. Moreover, recent studies have suggested that rainfall in tropical South America does not rely only on the moisture transport from oceanic sources, but also on vegetationatmosphere feedbacks related to precipitation recycling and evapotranspiration [8] and the action of biotic pump mechanisms [7].

The interannual variability of precipitation in northern South America is dominated by the El Niño Southern Oscillation (ENSO) ([9], and references therein), evidenced not only at interannual but also at diurnal time scales [9]. Although there are some spatial differences in timing and amplitude, the effects of ENSO on local hydroclimatology include reductions of rainfall, soil moisture, and river flow during its warm phase (El Niño), whereas opposite conditions are observed during its cold phase (La Niña) ([1, 10], and references therein). Despite the strong influence of the eastern equatorial Pacific, other oceans also influence precipitation over tropical South America. For example, the sea surface temperature (SST) in the tropical Atlantic influences local precipitation over the Amazon [11]. On the other hand, the main remote oceanic influence onto tropical South America precipitation is associated with the tropical Indian-Pacific oceans [12]. In addition, modulations of ENSO impact on subtropical South America summer climate by the Pacific Decadal Oscillation (PDO) has also been suggested [13]. However, due to the lack of longer records of rain gauge observations over northern South America, especially Colombia, the decadal and multidecadal variability of precipitation in this region is still not well identified.

The development of General Circulation Models (GCMs) has contributed to the improvement of our current knowledge about global and regional climate dynamics in South America, providing projections about their future conditions. Therefore, these models are an important tool for understanding climate variability in regions with scarce information. The last model generation gathered by the Coupled Model Intercomparison Project (CMIP5) includes 24 modeling groups around the world. These recent models have been demonstrated to perform a better representation of the mean state of atmospheric variables, such as surface temperature and precipitation, than their previous versions presented in the CMIP3 [14]. Recent studies have found that the double ITCZ bias has been reduced from CMIP3 models to CMIP5, although the cold tongue bias remains similar [15]. Though rainfall over the Amazon is still underestimated in some of the CMIP5 models [16], their representation of its annual cycle along with its spatial distribution and its covariability with SSTs over tropical oceans has improved [16].
The recent evaluation of general CMIP5 projections by the Working Group II of the Intergovernmental Panel on Climate Change (IPCC) has identified northern South America, especially Colombia, as one of the most vulnerable regions to be affected by climate change [17]. Furthermore, recent extreme wet seasons over the region have caused socioeconomic consequences of wide proportions [18]. Hence, a more detailed evaluation of the representation of local climate at seasonal and interannual time scales by the CMIP5 models is urgently required, in order to identify and analyze projections of regional and local future climate under a global climate change scenario. Therefore, this study aims to evaluate the representation of the seasonal mean precipitation over northern South America and its interannual variability, as well as the simulation of their main driving mechanisms, performed by the CMIP5 models. This paper is developed as follows: Section 2 describes the data and methods used, Section 3 presents the main results suggested by this work, and Section 4 presents a brief discussion and summary.

\section{Data and Methodology}

Since climate over tropical South America is the result of several phenomena influenced by both Atlantic and Pacific variability, we focused our study in the region located between $15^{\circ} \mathrm{S}-20^{\circ} \mathrm{N}$ and $120^{\circ} \mathrm{W}-0^{\circ} \mathrm{W}$. To address our analysis, we considered three reference precipitation datasets: one satellitederived dataset, one reconstructed dataset, and one reanalysis product. Reconstructed datasets are the combination of gauge and satellite measurements, involving statistical methods. On the other hand, reanalysis products are usually used to perform hindcast analysis by the inclusion of observations, numerical methods, and data assimilation techniques [19].

The satellite-derived dataset corresponds to the Tropical Rainfall Measurement Mission (TRMM) 3B43 V7 monthly dataset [20], with a spatial resolution of $0.25^{\circ}$ and available from 1998 to 2013 at the site http://mirador.gsfc.nasa.gov/.

The reconstructed dataset is the $2.5^{\circ} \times 2.5^{\circ}$ gridded monthly precipitation provided by the Global Precipitation Climatology Project (GPCP), version 2.2, available from 1979 to 2009 [21]. This dataset has been widely used over tropical South America and compared with other datasets like the Climate Prediction Center (CPC) and TRMM [22].

The reanalysis used in this study corresponds to the National Centers for Environmental Prediction (NCEP) Climate Forecast System Reanalysis (CFSR) [23]. CFSR data has a spatial resolution of $38 \mathrm{~km}$ and is available from 1979 to 2013 at the website http://nomads.ncdc.noaa.gov/thredds/ catalog/cfsrmon/catalog.html. This reanalysis has showed a superior performance of rainfall simulation than its previous versions NCEP/NCAR and NCEP/DOE reanalysis, reflecting a better representation of circulation fields [24]. It has been suggested that, due to its coupled data assimilation, CFSR reanalysis has a good representation of the atmosphereocean feedback processes related to ENSO, overcoming other reanalyses [25]. For this reason, we included the CFSR reanalysis as a useful tool for assessing the interannual variability of rainfall in northern South America, especially that associated with ENSO. 
TABLE 1: General description of the CMIP5 models used in this study.

\begin{tabular}{lcccc}
\hline Model & Institute & AGCM Lon $\times$ Lat resolution & Time period & References \\
\hline CCSM4 & National Center for Atmospheric Research (USA) & $1.25^{\circ} \times 0.9375^{\circ}$ & $1850-2005$ & Gent et al. 2011 [46] \\
\hline $\begin{array}{l}\text { FGOALS-g2 } \\
\text { Institute of Atmospheric Physics, Chinese } \\
\text { Academy of Sciences, and Tsinghua University } \\
\text { (China) }\end{array}$ & $2.8125^{\circ} \times 2.8125^{\circ}$ & $1850-2005$ & Li et al. 2013 [47] \\
\hline GFDL-ESM2M & NOAA/Geophysical Fluid Dynamics Laboratory & $2.5^{\circ} \times 2^{\circ}$ & $1861-2005$ & Dunne et al. 2012 [48] \\
\hline HadGEM2-CC & Met Office Hadley Centre (UK) & $1.875^{\circ} \times 1.24^{\circ}$ & $1860-2005$ & Collins et al. 2011 [49] \\
\hline HadGEM2-ES & Met Office Hadley Centre (UK) & $1.875^{\circ} \times 1.24^{\circ}$ & $1860-2005$ & Jones et al. 2011 [50] \\
\hline NorESM1-M & Norwegian Climate Centre (Norway) & $2.5^{\circ} \times 1.875^{\circ}$ & $1850-2005$ & Bentsen et al. 2013 [51] \\
\hline NorESM1-ME & Norwegian Climate Centre (Norway) & $2.5^{\circ} \times 1.875^{\circ}$ & $1850-2005$ &
\end{tabular}

The three reference datasets were compared with simulations from seven CMIP5 GCMs, selected following the criteria described in Section 3.1. The description and references for each of these models are given in Table 1. The period of analysis for climatological patterns and their interannual variability corresponds to the record (simulation) period for each observational dataset (model) used in this study.

For both, CMIP5 models and CFSR reanalysis, we examined monthly rainfall, horizontal winds, and SSTs. The model data corresponds to the historical experiments of the CMIP5 runs, which include natural and anthropogenic observed forcing in the period 1850-2005 [26]. CMIP5 data are available at the Program Climate Model Diagnosis and Intercomparison (PCMDI) website (http://pcmdi9.llnl.gov/). The models and reference data were regridded to a common $2.8125^{\circ}$ latitude by $2.8125^{\circ}$ longitude grid through bilinear interpolation, which corresponds to the coarser resolution among all datasets and models.

In order to evaluate the representation of the seasonal mean precipitation over northern South America by the selected CMIP5 models, we used Taylor diagrams [27], an error metric based on the Normalized Root Mean Squared Error (NRMSE), the Pattern Correlation Coefficient (PCC), and the ratio of the spatial variances between observations and simulations performed by each single model. The RMSE is a common measure of accuracy for field forecast, which operates over the gridpoints of a pair of simulation/observation fields and calculates a spatial average of individual squared differences between these two fields. The RMSE was normalized with the observed standard deviation for each season. Therefore, higher NRMSE values correspond to poor model simulations; by contrast, a high PCC value is related to a satisfactory model performance. The results obtained using this methodology were verified following the approach of Lee and Wang 2014 [28], which uses RMSE and PCC displayed into a scatter plot. Only the former is presented in this paper.

\section{Results and Analysis}

3.1. Preselection of the CMIP5 Models. In order to identify the CMIP5 members that exhibit the best representation of the annual and interannual variability of precipitation over tropical South America, we performed a preselection, based on literature review, of the CMIP5 models that show a better simulation of the main climate drivers over the region, previously discussed in Section 1. The criteria considered for this selection were (i) the representation of the basic features of ENSO (i.e., amplitude and spatial-temporal variability), (ii) the ability to simulate precipitation patterns over the Amazon, and (iii) the representation of rainfall patterns over surrounding oceans and mainland throughout the year. Here, we present the main summary obtained from literature review about these three criteria.

Regarding the first criterion, CMIP3 models display several biases in their simulations of ENSO, including (i) large differences in its amplitude, (ii) an overestimation of the 2-year frequency events instead of the 3-8-year observed frequency, (iii) a poor representation of the seasonal phase locking ([29], and references therein), (iv) the tendency to reproduce the central Pacific El Niño but with difficulties simulating the eastern Pacific ENSO, and (v) issues simulating these two events independently [30]. The main causes attributed in literature for these biases are the poor performance of the annual cycle and long-term mean of SSTs in the tropical Pacific [29] and the dry bias over the eastern Pacific exhibited by the CMIP3 models [30]. CMIP5 models have demonstrated a better performance in some features of ENSO, such as the simulation of the two types of ENSO events and the difference in their spatial patterns [30], and improvements in the representation of some relevant feedbacks like the SST-latent heat flux feedback [29]; however, other important characteristics are still poorly represented. Particularly, the precipitation anomaly over the central Pacific during ENSO events remains with substantial biases, as well as the wind-SST and shortwave-SST feedbacks [29]. Furthermore, the ENSO frequency is still not well captured by GCMs, especially for the 5-to-6-years period [31]. Previous studies have suggested that an accurate mean state in the equatorial Pacific is a very important factor for ENSO simulations ([30], and references therein). Particularly, the NorESM1-M version included in CMIP5 shows a good representation of the SST mean state over the eastern Pacific but significant cold biases over the western basin; on the contrary, CCSM4 has important warm biases over the eastern Pacific and smaller errors over the western Pacific while HadGEM2-ES presents a good simulation over the tropical Pacific, with some warm biases 
in the eastern part [32]. The amplitude of the ENSO signal is stronger in NorESM1-M, CCSM4, and GFDL-ESM2M, with spectral peaks reflecting a stronger periodic signal [32]. HadGEM2-ES also shows large ENSO amplitude but a more realistic extent of the spectral peaks [32]. On the other hand, though FGOALS-g2 successfully simulates the observed ENSO amplitude and period, it is unable to represent the central Pacific El Niño, due to the stronger negative cloud-shortwave feedback in this area [33]. Among the models that realistically represent both the eastern Pacific and central Pacific El Niño types are GFDL-ESM2M, HadGEM2ES, HadGEM2-CC, and NorESM1-M [34]. Furthermore, Bellenger et al. [29] show a generally good representation of the amplitude, structure, spectrum, and seasonality of ENSO simulations by NorESM1-M, NorESM1-ME, CCSM4, FGOALS-g2, HadGEM2-ES, and HadGEM2-CC (although they show some important biases in seasonality), as well as adequately represented feedbacks (e.g., Bjerknes, heat flux, shortwave, latent heat feedbacks) by FGOALS-g2 and CCSM4.

In relation to the second criterion, several studies have identified that the most of the CMIP5 models are able to represent the total rainfall amount over the Amazon during the wet season (DJF), but only HadGEM2-ES, HadGEM2CC, and CCSM4 can reproduce a good estimation of the precipitation quantities during the dry and transition seasons (JJA and SON, resp.) [24]. In addition, HadGEM2-ES and HadGEM2-CC also exhibit a seasonal spatial distribution of rainfall closer to that presented by observations, showing a simulation of surface conditions over the Amazon better than other models. On the other hand, CCSM4 shows an underestimation of convective moisture in the Amazon, which appears to be connected to excessive precipitation simulated over the Atlantic and Pacific ITCZs [24].

Finally, regarding the third selection criterion, CMIP5 models continue to exhibit important biases in the annual mean of tropical Atlantic SSTs due to a reversal of the SST zonal gradient, with exception of HadGEM2-ES and HadGEM2-CC models [35]. These biases have a similar evolution to those presented for the CMIP3 models, which consist in a weakening of the easterlies over the Atlantic during MAM and a subsequent deepening of the eastern thermocline, increasing the SSTs and reducing the cooling during the main upwelling season (JJA). The main cause for these biases appears to be the latitudinal location of the Atlantic ITCZ, which influences the strengthening of the easterlies. CMIP5 models show a larger latitudinal range of the ITCZ location over the Atlantic Ocean, from $6^{\circ} \mathrm{S}$ to $8^{\circ} \mathrm{N}$ during AprilAugust, in comparison to the observed ITCZ migration, which covers the range between $0^{\circ}$ and $8^{\circ} \mathrm{N}$ [35]. Particularly, HadGEM2-CC shows the highest Taylor skill score in reproducing the annual mean precipitation over tropical oceans [15]. Furthermore, Hirota and Takayabu (2013) [15] identified that FGOALS-g2 and GFDL-ESM2M exhibit the most significant double ITCZ bias. By contrast, NorESM1-M and HadGEM2-CC show a good representation of the SSTs and ITCZ location over the Pacific Ocean. Finally, although HadGEM2-ES displays one of the smallest double ITCZ biases, its cold tongue bias is still significant.
According to the discussion addressed above, we selected seven CMIP5 models, as listed in Table 1 (NorESM1M, NorESM1-ME, CCSM4, GFDL-ESM2M, FGOALS-g2, HadGEM2-ES, and HadGEM2-CC), in order to perform the analysis presented in the following sections.

3.2. Rainfall Seasonality over Northern South America. The following sections evaluate and discuss the representation of the annual cycle of precipitation over northern South America and surrounding oceans by the selected CMIP5 models. Figure 1 shows the spatial pattern of the seasonal mean rainfall in the study region for the seven CMIP5 models and the three observation datasets considered. To complement this analysis, Figure 2 displays the climatological differences between models and reference datasets with respect to TRMM data.

The spatial distribution of rainfall for the three observation datasets are in agreement with all seasons, although there are differences in rainfall amplitude, especially over the oceanic ITCZ (Figures 1 and 2). Furthermore, precipitation values given by CFSR over the continent are generally larger than those of TRMM and GPCP in MAM, and smaller in DJF, JJA, and SON. By contrast, TRMM and GPCP values are much closer. As it has been previously established, although the Southern Hemisphere (SH) is hotter in DJF, the observed ITCZ is located to the north of the Atlantic and Pacific Oceans, due to the combination of several ocean-atmosphere mechanisms that keep the ITCZ north of equator [37]. Because of the absence of these mechanisms over mainland, the continental ITCZ in the Americas is located over the $\mathrm{SH}$ in DJF [37]. Results indicate that all models are able to locate the ITCZ in southern South America but they disagree on locating the maximum rainfall centers. NorESM1-M, NorESM1-ME, and CCSM4 present the center of maximum rainfall eastward of the location indicated by observations, concentrating precipitation in this part of the continent, leading to dry biases over the western flank of the continent and wet biases over the east. By contrast, HadGEM2-ES, HadGEM2-CC, FGOALS-g2, and GFDL-ESM2M are able to locate the maximum precipitation over the central part of the Amazon, although FGOALS-g2 and GFDL-ESM2M significantly underestimate their values with respect to TRMM rainfall. In addition, only three models (FGOALS-g2, HadGEM2-ES, and HadGEM2-CC) maintain the ITCZ over the northern Atlantic and Pacific Oceans in boreal winter (DJF). Previous studies suggest that an erroneous demise of the ITCZ from the Northern Hemisphere (NH) in boreal winter and spring observed in models is associated with biases in simulated air-sea feedbacks [38]. Hence, the correct location of the ITCZ in DJF exhibited by some models could imply a better representation of such ocean-atmosphere feedbacks. Since models locate the Pacific ITZC southward of the location indicated by observations (with the exception of the two HadGEM2 models, FGOALS-g2, and CCSM4), their simulation of the maximum rainfall center over the northwestern Colombian coast in DJF is also simulated southward of its observed location. 

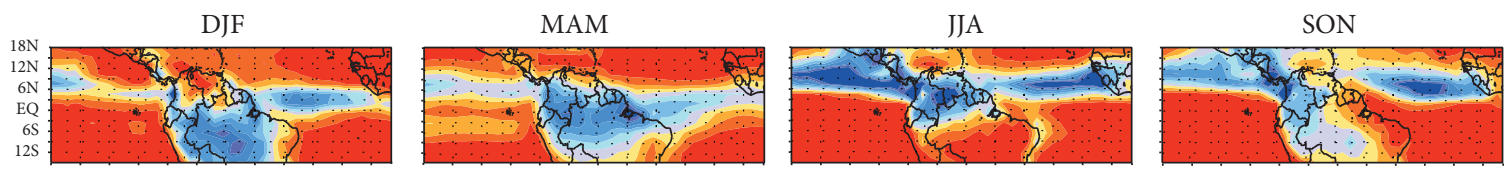

$\left(a^{*}\right)$
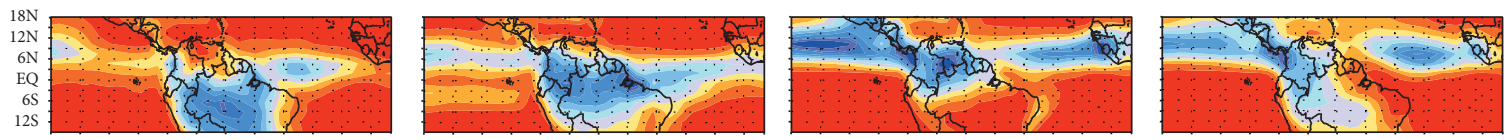

$\left(b^{*}\right)$
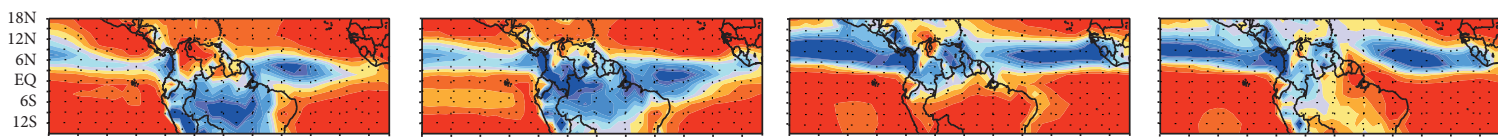

$\left(c^{*}\right)$
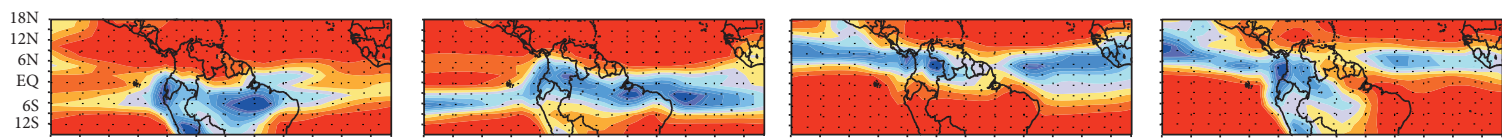

(d)
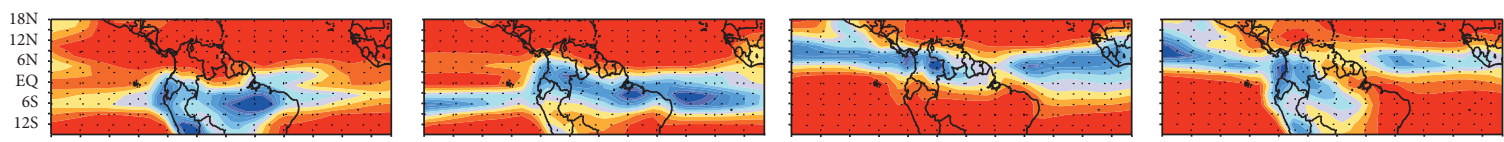

(e)
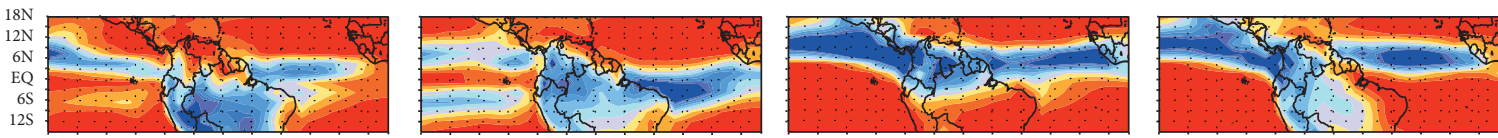

(f)
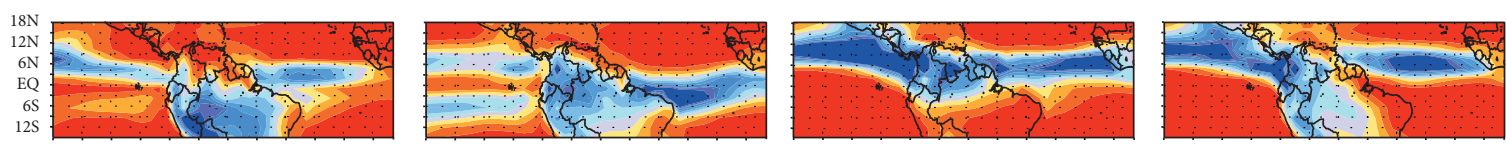

(g)
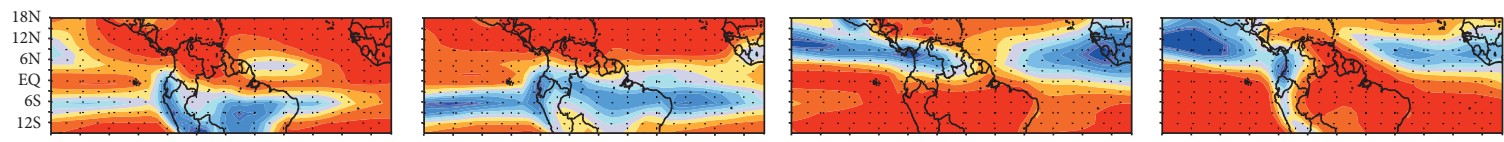

(h)
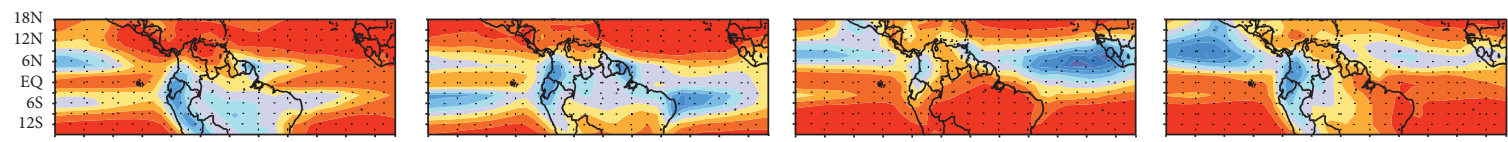

(i)
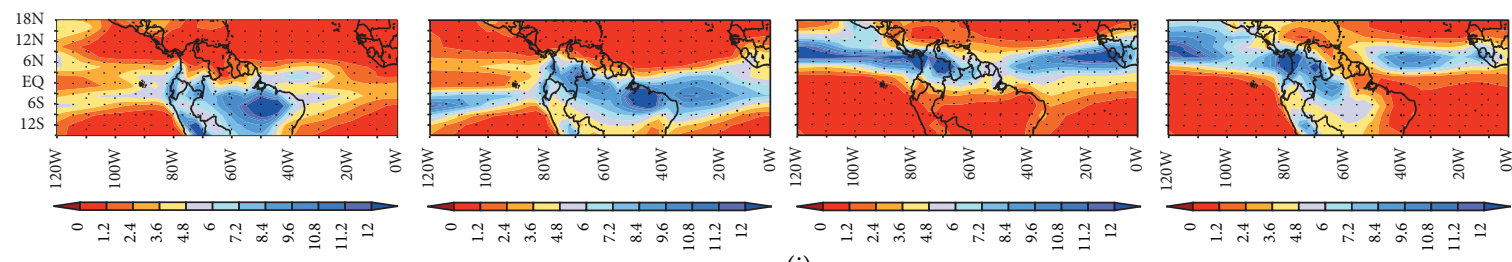

(j)

Figure 1: Seasonal mean precipitation flux (mm/day) over northern South America ((a) TRMM, (b) GPCP, (c) CFSR, (d) NorESM1-ME, (e) NorESM1-M, (f) HadGEM2-ES, (g) HadGEM2-CC, (h) GFDLESM2M, (i) FGOALS-g2, and (j) CCSM4). The asterisks indicate the reference datasets. 

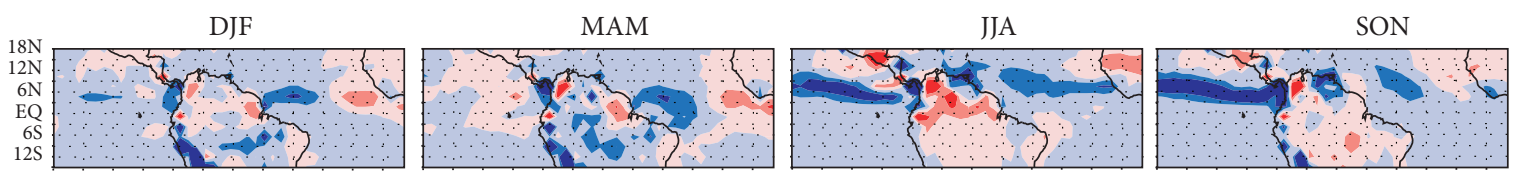

$\left(\mathrm{a}^{*}\right)$
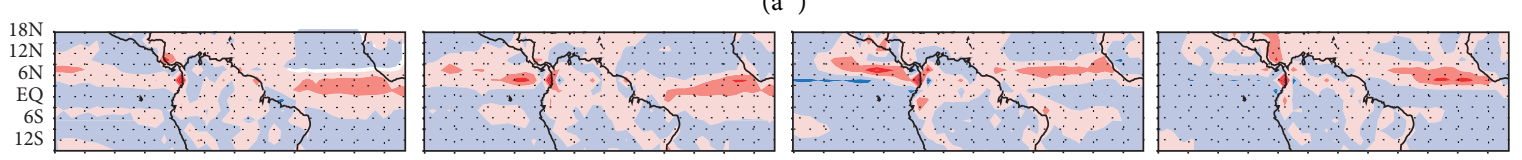

$\left(b^{*}\right)$
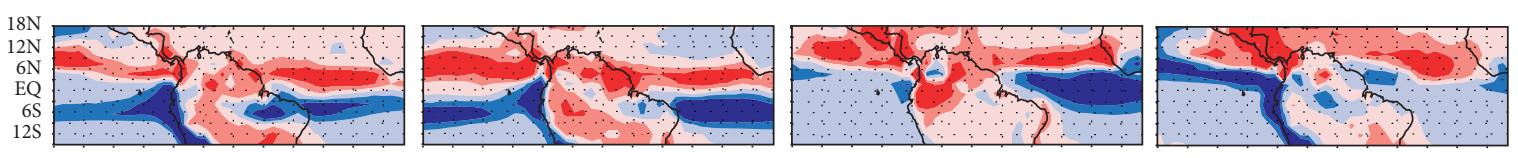

(c)
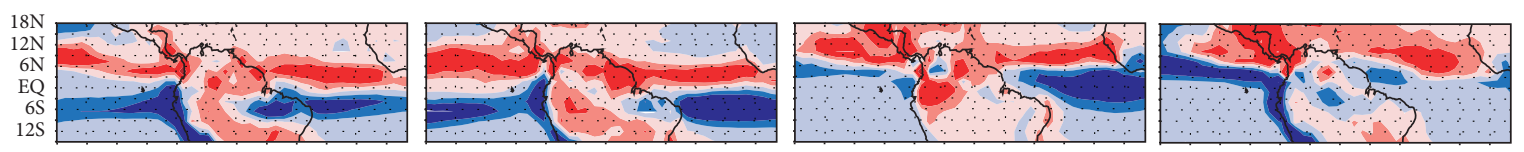

(d)
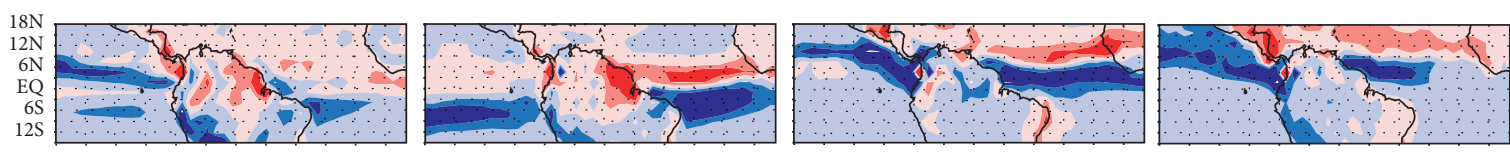

(e)
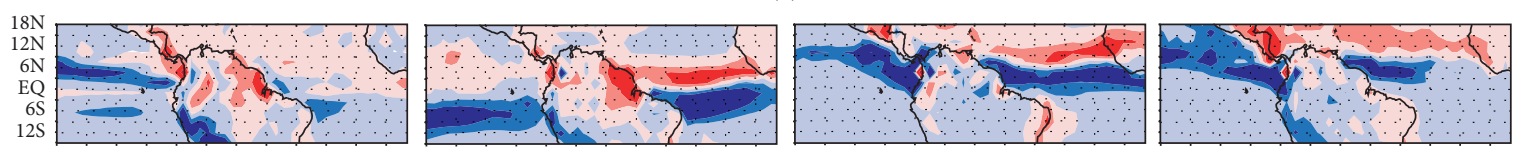

(f)
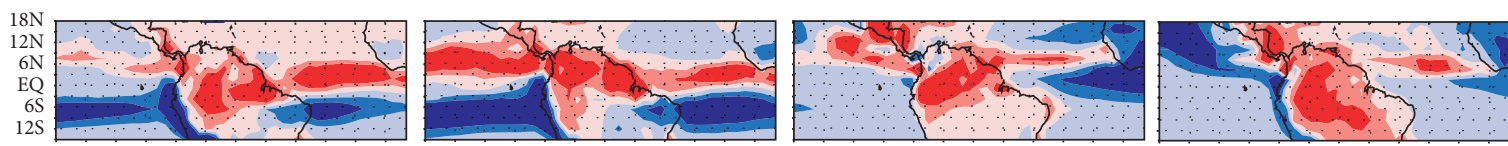

(g)
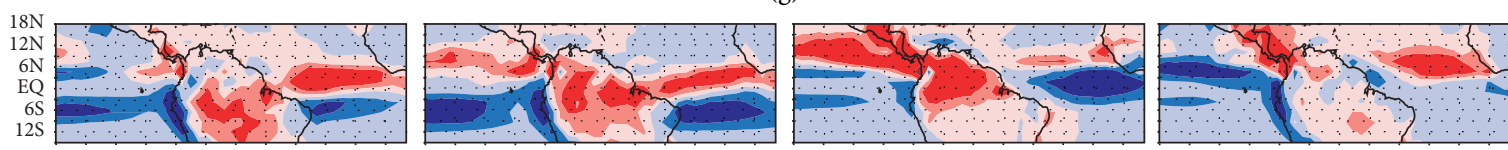

(h)
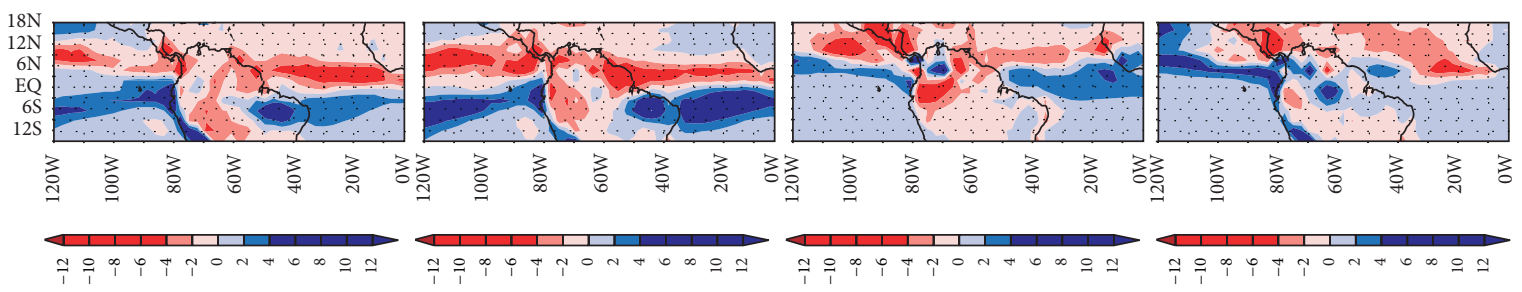

(i)

FIGURE 2: Climatology seasonal differences of precipitation flux ( $\mathrm{mm} /$ day) over northern South America with respect to TRMM ((a) CFSR, (b) GPCP, (c) NorESM1-ME, (d) NorESM1-M, (e) HadGEM2-ES, (f) HadGEM2-CC, (g) GFDLESM2M, (h) FGOALS-g2, and (i) CCSM4). The asterisks indicate the reference datasets.

In boreal spring (MAM), the southeastern tropical Pacific exhibits the double ITCZ phenomenon due to the heat accumulation and the convective responses related [39]. As shown in Figure 1, observed rainfall over this region of the Pacific Ocean is larger in MAM than in DJF. Furthermore, the Pacific ITCZ is simulated over the $\mathrm{SH}$ by most of the models, with the exception of HadGEM2-ES, HadGEM2-CC, and FGOALS-g2, which reproduce both the northern and southern Pacific ITCZ; however, rainfall intensities in the southern ITCZ show larger values than observed (Figures 1 and 2). The seven CMIP5 models selected locate the MAM Atlantic ITCZ southward of its real position, inducing wet biases south 
of the equator and dry biases over the Atlantic warm pool. Over the continent, the best representation of MAM rainfall spatial pattern and amplitude is shown by HadGEM2-ES, HadGEM2-CC, and GFDL-ESM2M.

Finally, results indicate that it is easier for models to reproduce rainfall distribution during boreal summer and fall (JJA and SON, resp.) over both oceans and land. This is probably due to the fact that during these seasons, the incoming radiation and the ocean-atmosphere feedbacks over Atlantic and Pacific Oceans locate the ITCZ on the NH. Consequently, the model representation of the maximum rainfall center over western Colombia is much more accurate for JJA and SON than for other seasons. Over the Atlantic Ocean, HadGEM2-ES, HadGEM2-CC, and CCSM4 exhibit the closest representation of the spatial precipitation pattern. However, the seven models display an overestimation of precipitation in the eastern tropical Atlantic $\left(3^{\circ} \mathrm{N}-3^{\circ} \mathrm{S}\right)$, especially in JJA. This has been observed in CMIP3 models and has been associated with a misrepresentation of the cold tongue onset in this ocean [40]. The best simulation of the rainfall spatial pattern and amplitude over the Atlantic Ocean is observed during SON for all models. Only GFDLESM2M exhibits a dry bias over most of the continental area in this season; this behavior has been linked to the excessive rainfall over the tropical Atlantic and/or Pacific simulated by this model [24]. Furthermore, the seven models are able to identify the Amazon dry season during JJA (Figure 1), with generally small differences with respect to TRMM data, by exception of HadGEM2 models, which overestimate Amazon dry season rainfall (Figure 2).

3.3. Interannual Variability and Annual Cycle of Precipitation. An adequate representation of seasonal precipitation over a given region does not only rely on the simulation of climatological mean patterns, but also on the simulation of rainfall variability patterns. To identify if the seven selected models are able to realistically simulate the areas with the largest interannual variability of rainfall in the study region, Figure 3 shows the seasonal standard deviation of precipitation for all models and observation datasets. Similar to precipitation climatology (Figure 1), the three reference datasets agree to identify the regions with the largest variability in all seasons, although CFSR exhibits much larger standard deviations over the equatorial Atlantic and Pacific Oceans and northern South America (Figure 3). It can be noticed that, in general, the regions with the largest rainfall amounts match those displaying the largest standard deviations (Figures 1 and 3). This is a well-known relationship observed in both model simulations and observations and discussed in previous studies. However, the DJF standard deviation of observations shows a region of large variability over the tropical Pacific, between $110^{\circ} \mathrm{W}$ and $120^{\circ} \mathrm{W}$ (Figure 3), that does not correspond to a region with large rainfall amounts (Figure 1). Only NorESM1-M, NorESM1-ME, GFDL-ESM2M, and CCSM4 reproduce such large variability over the central tropical Pacific, although they show a different amplitude, extent, and location than observations. We explored the possible mechanisms associated with this large rainfall variability center later in this section. FGOALS-g2 underestimates rainfall interannual variability over the region of study in all seasons. During MAM, the large variability centers over the continent exhibited by observations are located in northeastern Brazil and the western coast of Ecuador. All models (except FGOALS-g2) follow this spatial pattern over mainland. Over tropical oceans, models tend to follow the spatial pattern of their climatological seasonal rainfall simulations (Figure 1). Accordingly, only the HadGEM2 models are able to reproduce the oceanic rainfall variability observed north of the equatorial line due to their ability to maintain the ITCZ north of the equator. The associated large variability area identified over the equator in DJF remains in observations during MAM. For the last two seasons of the year (JJA and SON), the distribution of the standard deviation is closely related to the spatial pattern of rainfall climatology; thus, all models are able to reproduce such pattern. However, during JJA, the region with the largest interannual variability over the tropical Atlantic, as indicated by observational datasets, is further north than that shown by models. The latter is probably due to the large precipitation amounts observed in model simulations over this region, which appears to be related to the lack of the cold tongue onset in this season, as discussed in the previous section.

Figure 3 suggests the existence of regions with large rainfall interannual variability within the domain considered for this study. In order to explore the dominant modes of variability associated with this rainfall standard deviation pattern and their corresponding frequencies, we selected the four regions with the largest standard deviations: (i) the central tropical Pacific $\left(2.5^{\circ} \mathrm{N}-2.5^{\circ} \mathrm{S}, 170^{\circ} \mathrm{W}-110^{\circ} \mathrm{W}\right)$, (ii) the Amazon $\left(5^{\circ} \mathrm{S}-10^{\circ} \mathrm{S}, 50^{\circ} \mathrm{W}-60^{\circ} \mathrm{W}\right)$, (iii) the eastern tropical Pacific, and (iv) the tropical Atlantic, as shown in Figure 4. To identify the main variability modes in each region and their contribution to total rainfall variability during the time period of analysis, we performed the Fast Wavelet Transform [36] to the domain average monthly precipitation estimated over each region for all datasets and models (Figure 5). NorESM1-M and HadGEM2-CC spectra are not shown due to their similarities with the other models from the same institute.

Previous studies have identified that rainfall over the central tropical Pacific shows strong variability related to ENSO, with enhanced (reduced) precipitation during its warm (cold) phase [41]. Our results indicate that the largest contributions to variance observed in the central tropical Pacific correspond to the frequencies of 2-4 and 4-8 years, suggesting that the large standard deviation in this region shown in Figure 3 is associated with ENSO. Furthermore, power spectra obtained from observational datasets show important contributions to rainfall variability in the central tropical Pacific during 1982-1987 and 1997-1998 (Figure 5), when warm ENSO events occurred [42]. In addition, TRMM data shows a strong spectral peak associated with La Niña 2010-2011. FGOALS-g2 is the only model that can reproduce these two variability frequencies as the main contributors to total rainfall variability in this region. In particular, this model shows enhanced ENSO activity during the 1920s, 1940-1960, and from the 1980s to present. On the other hand, GFDL-ESM2M simulation shows that the largest contributions to variance 

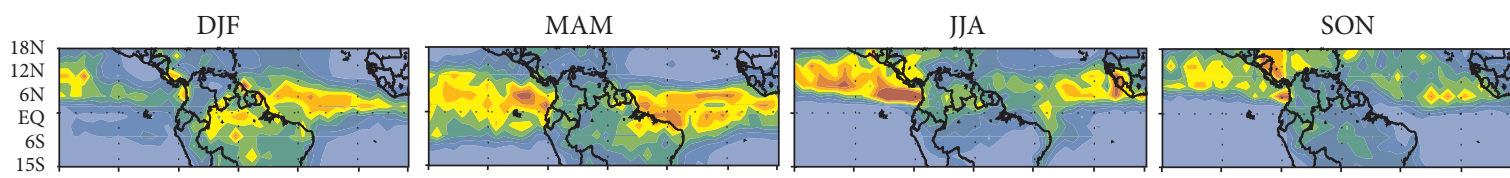

$\left(\mathrm{a}^{*}\right)$
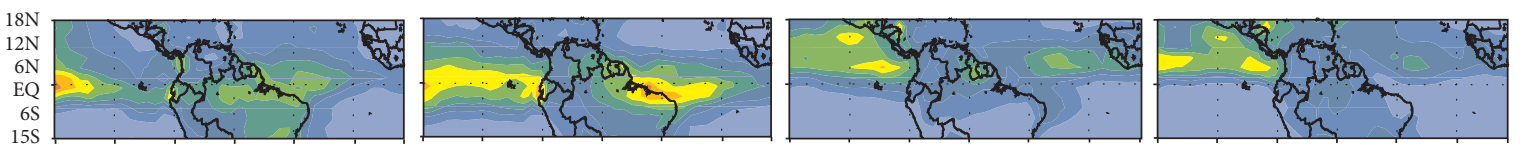

$\left(b^{*}\right)$
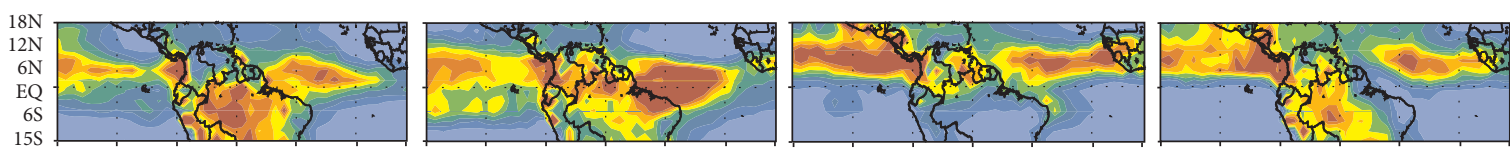

$\left(c^{*}\right)$
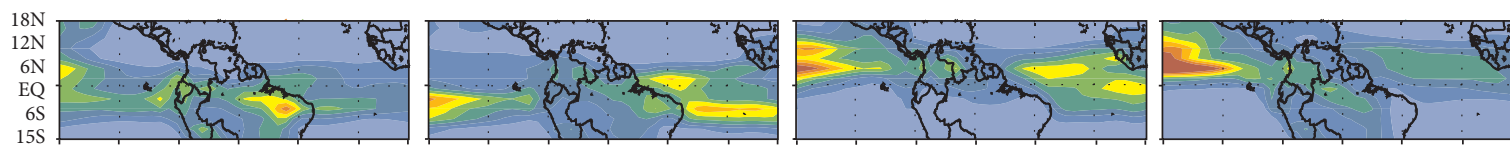

(d)
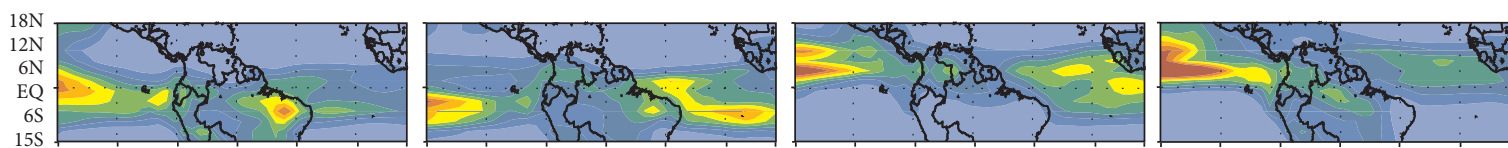

(e)
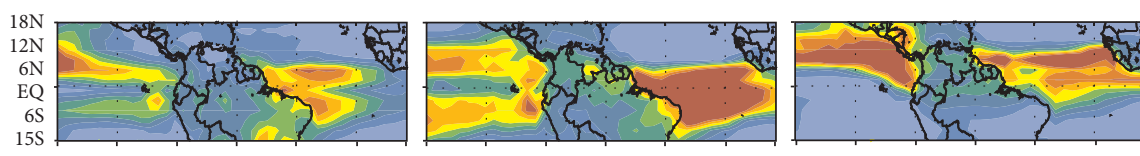

(f)
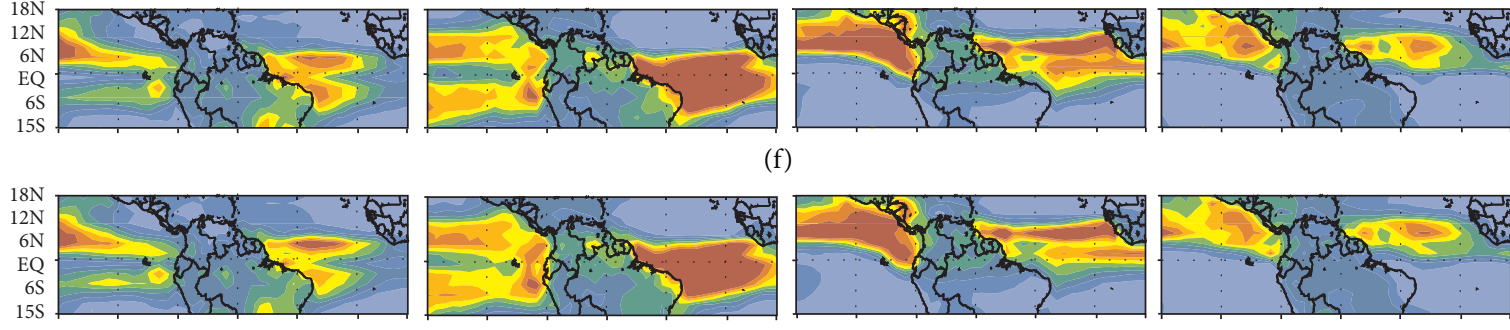

(g)
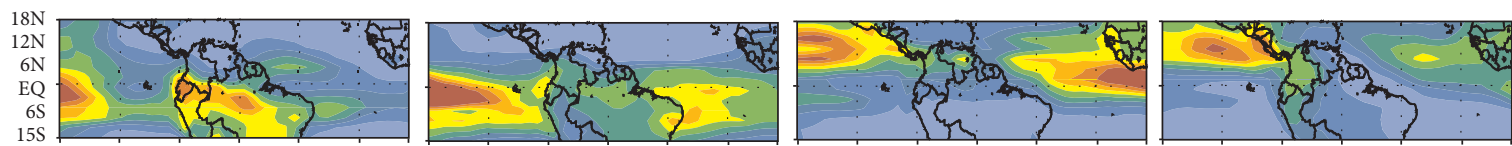

(h)
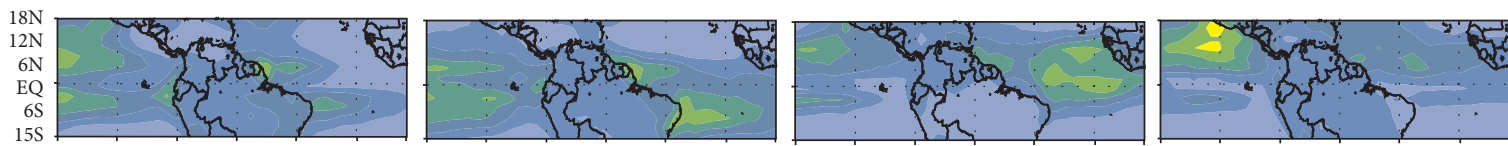

(i)
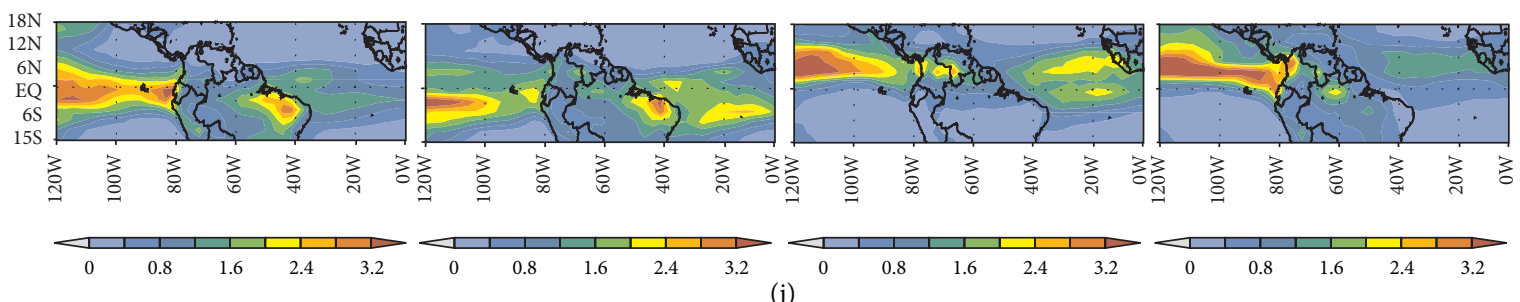

(j)

FIGURE 3: Seasonal standard deviation of precipitation flux (mm/day) over northern South America (a) TRMM, (b) GPCP, (c) CFSR, (d) NorESM1-ME, (e) NorESM1-M, (f) HadGEM2-ES, (g) HadGEM2-CC, (h) GFDLESM2M, (i) FGOALS-g2, and (j) CCSM4. The asterisks indicate the reference datasets. 


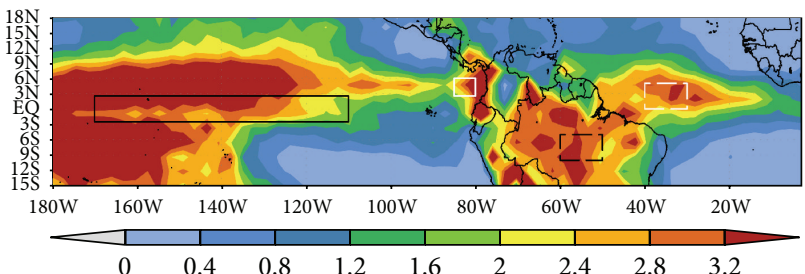

FIGURE 4: Standard deviation of rainfall for DJF ( $\mathrm{mm}$ /day) according to CFSR data. Boxes represent the regions of interest for the interannual variability analysis presented. Region 1: central tropical Pacific (black solid line), Region 2: Amazon (black dashed line), Region 3: eastern tropical Pacific (white solid line), Region 4: tropical Atlantic (white dashed line).

in the central tropical Pacific are concentrated in the 4year frequency range, while HadGEM2-ES misrepresents this frequency range with a dominant mode in 1-year frequency. In addition, NorESM1-ME shows most of the rainfall variability over this region associated with the 2-4-year mode while the CCSM4 exhibits that associated with the 4-8-year mode. Figure 5 indicates that the best location in time of the dominant frequencies contributing to rainfall variance in the central tropical Pacific is given by FGOALS-g2.

Figure 5 also shows that the dominant mode of rainfall variability in the Amazon, not only in observations but also in model simulations, corresponds to the annual cycle of precipitation over the region. In addition, observational datasets and models show the well-known relationship between Amazon rainfall and ENSO, reported in previous studies [43], as indicated by the $2-4$ and $4-8$ years frequency bands observed in their Wavelet power spectra. Furthermore, TRMM, GPCP, and CFSR datasets show discrepancies identifying the main frequency bands in the eastern tropical Pacific. Although the three datasets show the strong annual cycle and the ENSO influence in precipitation over the eastern tropical Pacific, they disagree about the main frequency of variability (Figure 5). Models are able to identify the annual cycle or precipitation in the eastern equatorial Pacific as the main variability mode as well as the ENSO signal at the same frequencies observed in the central Pacific region; however, some models (NorESM1-ME, CCSM4, and GFDL-ESM2M) display a high intraseasonal variability that is much weaker in observations. Finally, the main mode of rainfall variability over the tropical Atlantic identified by observations and models is the annual cycle, which has been previously recognized as the main variability mode in this region [44]. This mode of variability is well reproduced in models, except GFDL-ESM2M and CCSM4, which are dominated by a seasonal mode of variability over the region.

These results suggest the ability of several of the selected CMIP5 models to adequately represent, not only seasonal mean precipitation over northern South America, but also interannual variability in the regions with the largest standard deviations throughout the year. To further identify if these selected models are also able to simulate annual rainfall variability over the continent, we evaluated their representation of the annual cycle of precipitation in four regions: the Amazon $\left(75^{\circ} \mathrm{W}-60^{\circ} \mathrm{W} ; 3^{\circ} \mathrm{N}-10^{\circ} \mathrm{S}\right)$, Central Colombia (i.e., the tropical Andean region, $76^{\circ} \mathrm{W}-73^{\circ} \mathrm{W}, 8^{\circ} \mathrm{N}-3^{\circ} \mathrm{N}$ ), the Colombian Pacific coast $\left(80^{\circ} \mathrm{W}-76^{\circ} \mathrm{W}, 9^{\circ} \mathrm{N}-2^{\circ} \mathrm{N}\right)$, and northern Colombia (i.e., the Colombian Caribbean region, $76^{\circ} \mathrm{N}-$ $70^{\circ} \mathrm{N}, 12^{\circ} \mathrm{N}-8^{\circ} \mathrm{N}$; Figure $6(\mathrm{a})$ ).

As documented in previous studies, the Amazon region exhibits a clear unimodal annual cycle of precipitation, with peak values in March to May and minimum rainfall in July to September over its northernmost domain (Figure 6(b)) [2]. However, CFSR rainfall intensities are larger than those presented by TRMM and GPCP in the wet season and smaller in the dry season, as also suggested by Figure 1. This unimodal pattern is reproduced by the HadGEM2 models, which show amplitudes much closer to observations than those from other models. The other models exhibit a bimodal pattern, which differs from observations, and underestimate the annual cycle amplitude during almost the entire year (especially GFDL-ESM2M in SON). The dry bias exhibited by GFDL-ESM2M over the Amazon is reported in other studies [24].

The tropical Andean region in central Colombia shows a bimodal pattern of precipitation (Figure 6(b)), with larger rainfall amplitudes during May and October in TRMM and GPCP, and April and November in CFSR. CFSR values in this region are much smaller than those from the other observational datasets. All models (except the HadGEM2 and CCSM4 models) exhibit this two-peak pattern; however, GFDL-ESM2M shows a delayed first peak in June and a delayed second peak in October, which differs to the reference datasets. The FGOALS-g2 shows the more realistic rainfall amplitudes over the region during December-April, while the other models significantly underestimate rainfall over the tropical Andes during these months, with exception of the HadGEM2 models.

The Colombian Pacific region exhibits a bimodal pattern with maximum rainfall in April and October, as shown by the CFSR (Figure 6(b)). By contrast, the TRMM and GPCP patterns do not show a bimodal cycle since they suggest almost the same rainfall amounts between May and November (Figure 6(b)). The HadGEM2 and CCSM4 models show a unimodal annual cycle over this region rather than a bimodal pattern, in agreement with TRMM and GPCP data. The other models show a bimodal annual cycle of precipitation, with the second peak in the year larger than the first one. As in the Andean region, models that display a better simulation of the Pacific ITCZ display the less underestimated precipitation during DJF.

Finally, observational datasets indicate a precipitation cycle in the Colombian Caribbean region with peaks in May and October, as reported by IDEAM (2005) and other studies [45]; however, CFSR exhibits smaller rainfall intensities in these months in comparison to TRMM and GPCP. By contrast, some models exhibit a unimodal rainfall pattern (CCSM4, GFDL-ESM2M, and NorESM1 models), underestimating the precipitation during the first months of the year. These models correspond to those that are unable to maintain the ITCZ north of equator during DJF, as identified in Figure 1, suggesting a relationship between an adequate ITCZ location in the first months of the year and a realistic representation of the annual cycle of precipitation in the Caribbean 

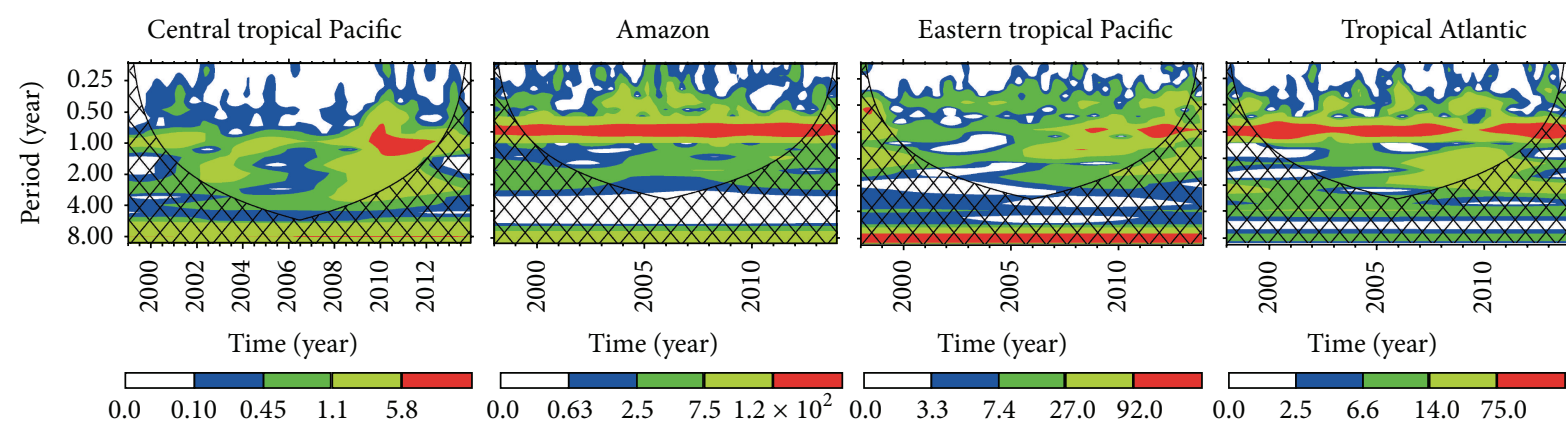

Time (year)

$\left(\mathrm{a}^{*}\right)$
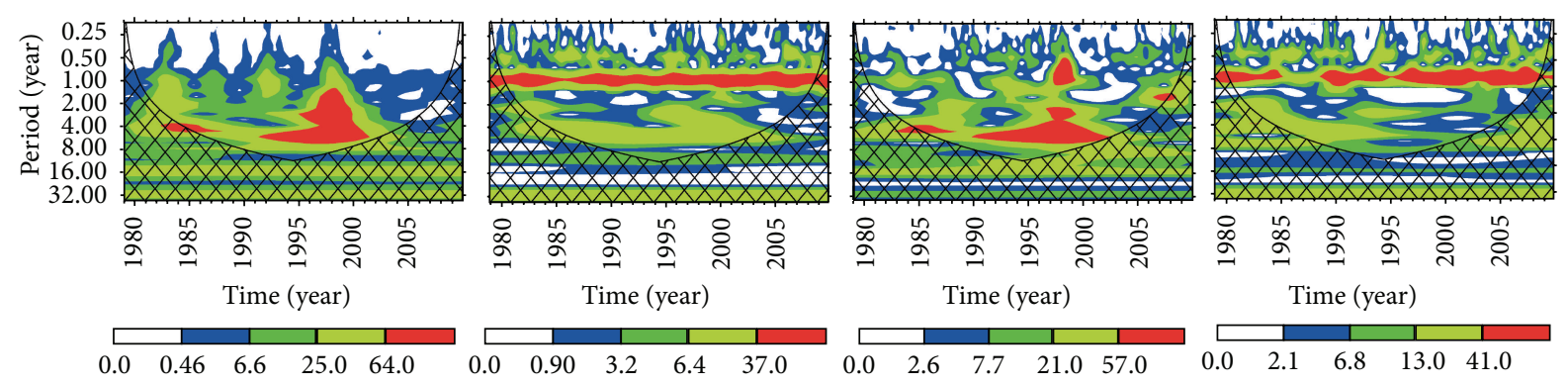

ஓ

Time (year)

Time (year)

$\left(b^{*}\right)$

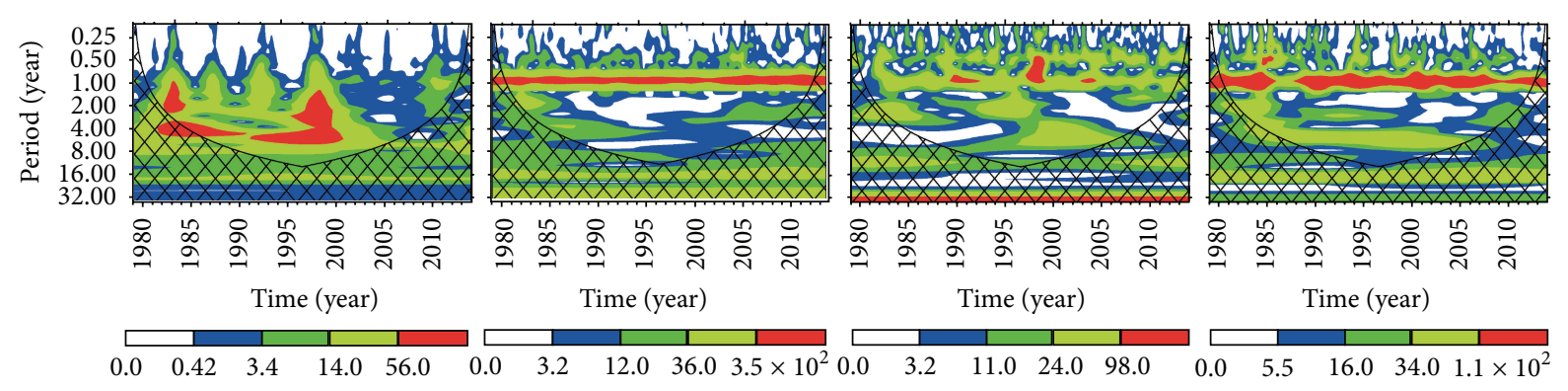

$\left(c^{*}\right)$

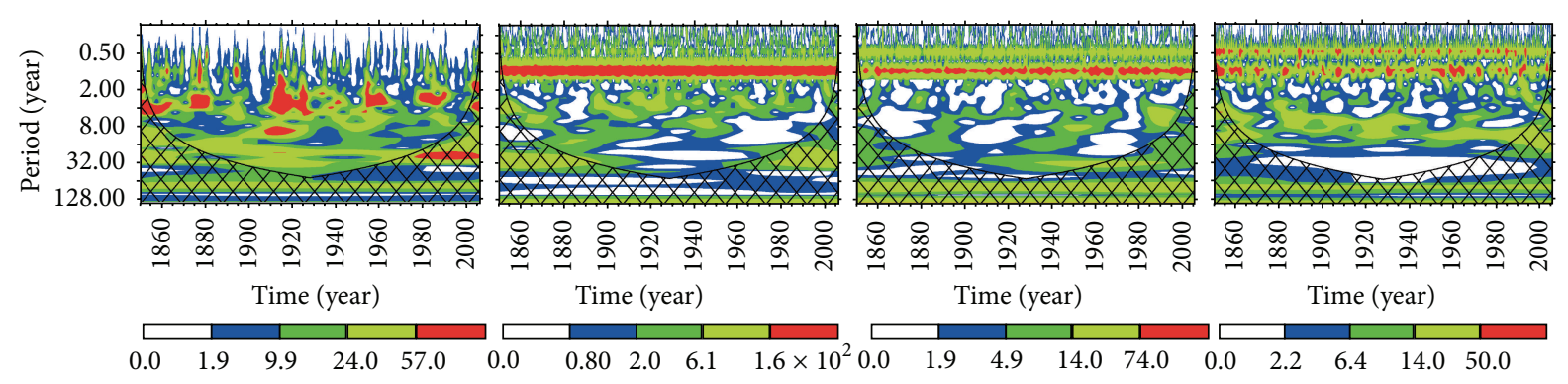

(d)
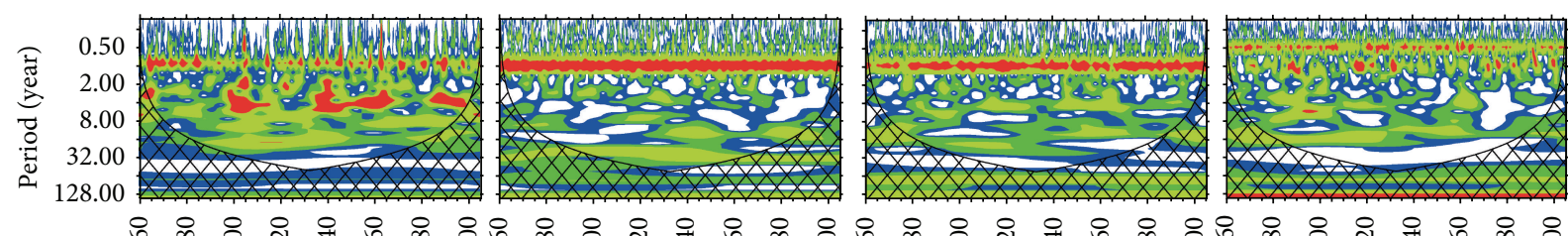

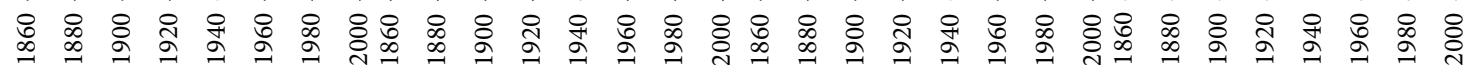
Time (year)

Time (year)

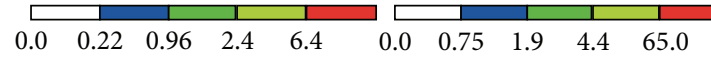

Power $\left((\mathrm{mm} / \text { day })^{2}\right) \quad$ Power $\left((\mathrm{mm} / \text { day })^{2}\right)$ Time (year)

Time (year)

FIgURE 5: Continued. 

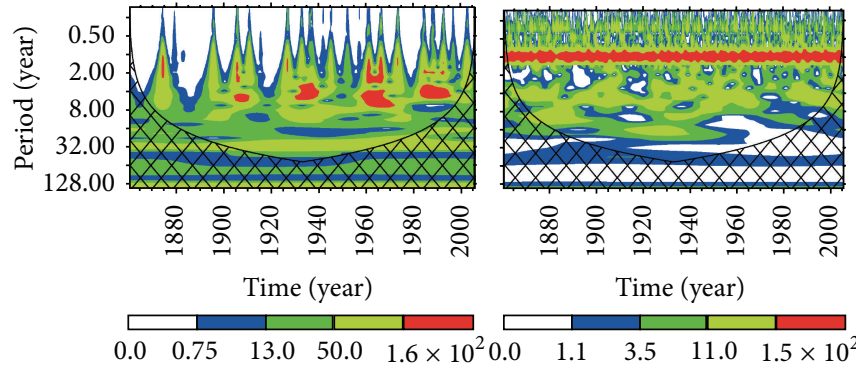

Time (year)

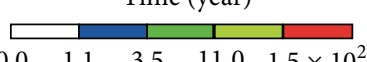

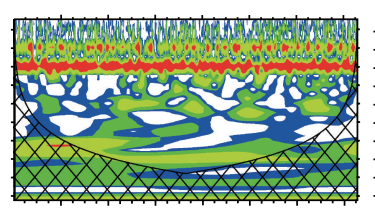

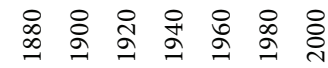

Time (year)

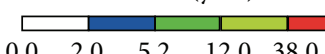

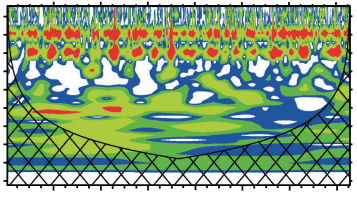

: ঃ Time (year)

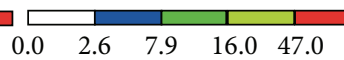

(f)
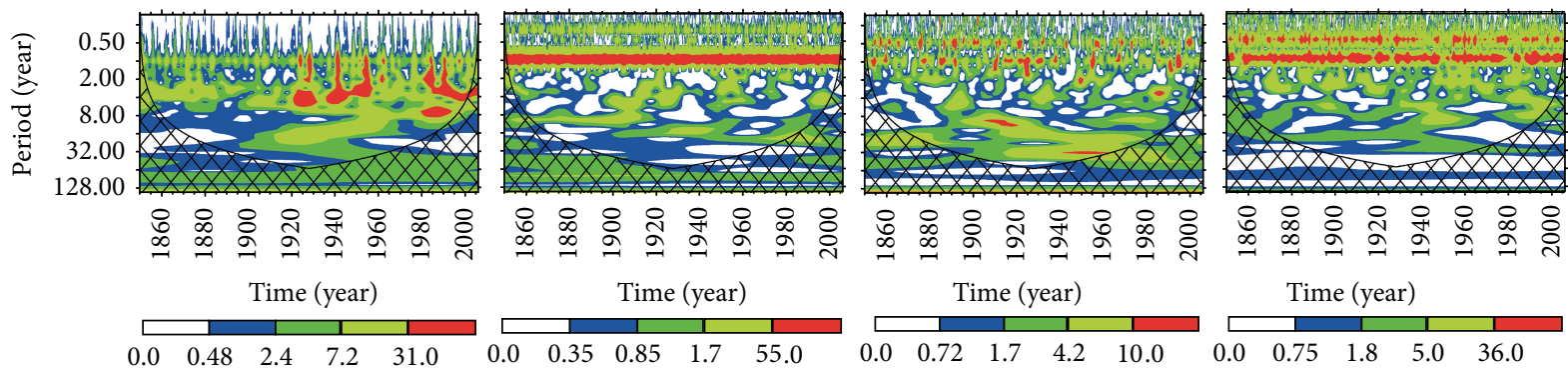

(g)
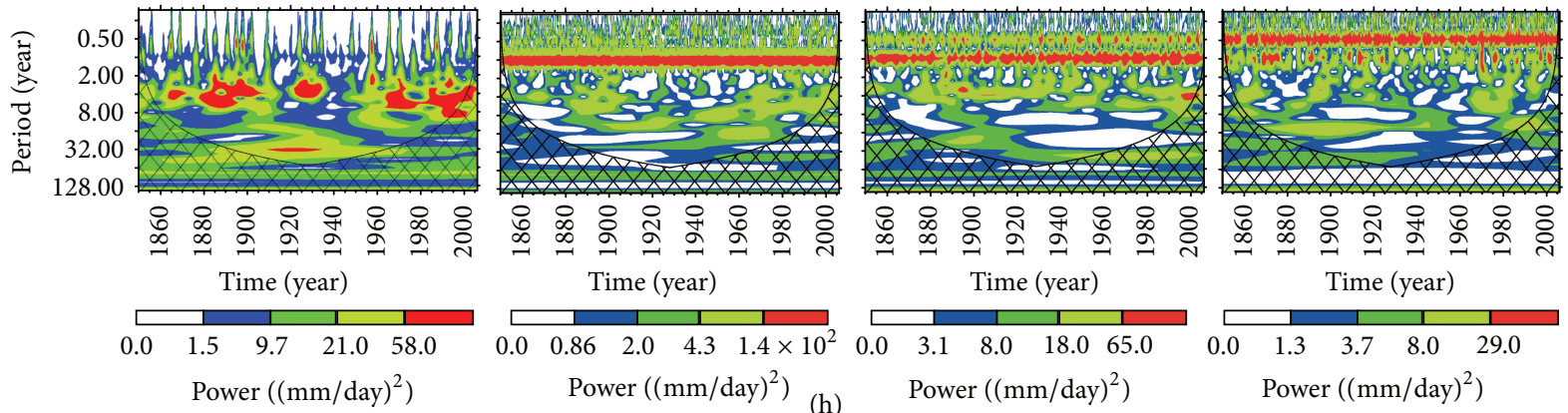

FIGURE 5: Wavelet power spectrums for seasonal rainfall in the four regions of interest shown in Figure 4 ((a) TRMM, (b) GPCP, (c) CFSR, (d) NorESM1-ME, (e) HadGEM2-ES, (f) GFDLESM2M, (g) FGOALS-g2, and (h) CCSM4). The asterisks indicate the reference datasets. Spectra were obtained from http://paos.colorado.edu/research/wavelets/, based on Torrence and Compo [36].

region. Although HadGEM2 models and FGOALS-g2 exhibit a bimodal pattern, only the latter is able to appropriately locate the two observed rainfall peaks in the year.

3.4. Evaluation of the CMIP5 Simulations. The results presented in Figures 1 to 6 qualitatively describe the simulations of the seasonal precipitation over northern South America performed by the seven CMIP5 models selected. In order to quantitatively evaluate such simulations, Figure 7 shows the corresponding Taylor diagrams for seasonal rainfall climatology considering TRMM as reference data, as described in Section 2. GPCP seasonal rainfall is much closer to TRMM than CFSR, as also shown by Figure 2. The models with the best representation of seasonal rainfall over northern South America (i.e., those showing the least RMSE and standard deviation ratio, and PCC closer to one) are the HadGEM2 models, especially in DJF and MAM. The worse simulations are produced in MAM, when all models either exhibit the double ITCZ bias or locate the ITCZ over the SH rather than over the NH (Figure 1). Since the FGOALS-g2 underestimates the standard deviation ratio in all seasons, it tends to underestimate the spatial variability of precipitation over northern South America, especially during MAM (Figure 3). However, since this model reproduces a seasonal rainfall pattern reasonably in agreement with observations (Figure 1), PCC values for this model are relatively large. In JJA and SON, models show smaller RMSE and larger PCC values, and thus a better simulation of seasonal rainfall over the domain considered. This is due to the ability of models to show a more realistic rainfall distribution over the region when the ITCZ is located north of the Equator, as discussed in Section 3.2. However, the standard deviation ratio shown by most of the models is not close to one, since observed rainfall intensities are larger during these seasons and only the HadGEM2 models are able to reproduce such high intensities (Figures 1 and 7).

These results indicate that, among the seven CMIP5 models selected, the HadGEM2 models show the more realistic simulations of seasonal and annual rainfall in northern South America. In addition, some of the models included in the CMIP5 archives still show a large double ITCZ bias over the tropical Pacific. Such a bias could affect rainfall simulation 


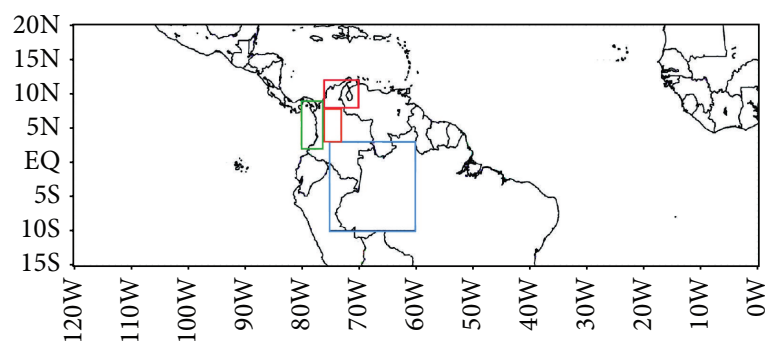

(a)

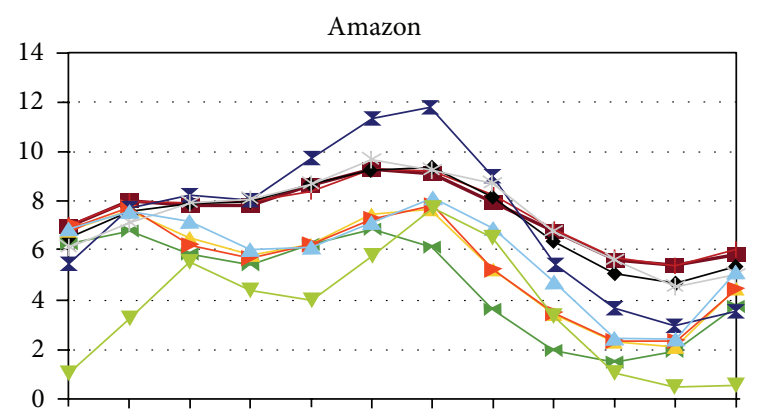

Oct. Nov. Dec. Jan. Feb. Mar. Apr. May. Jun. Jul. Aug. Sep.

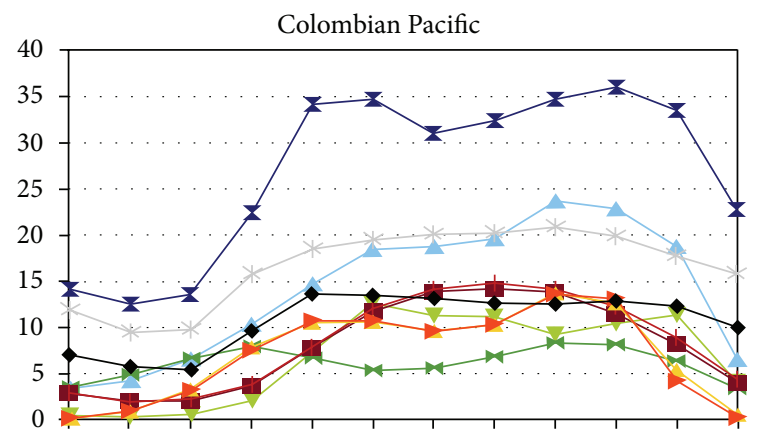

Jan. Feb. Mar. Apr. May. Jun. Jul. Aug. Sep. Oct. Nov. Dec.

$\begin{array}{ll}\rightarrow-\text { FGOALS-g2 } & - \text { CFSR } \\ \rightarrow-\text { HadGEM2-CC } & \rightarrow \text { GPCP } \\ \rightarrow \text { HadGEM2-ES } & * \text { TRMM } \\ \rightarrow-\text { NorESM1ME } & - \text { CCSM4 } \\ \rightarrow-\text { NorESM1M } & \rightarrow \text { GFDLESM2M }\end{array}$

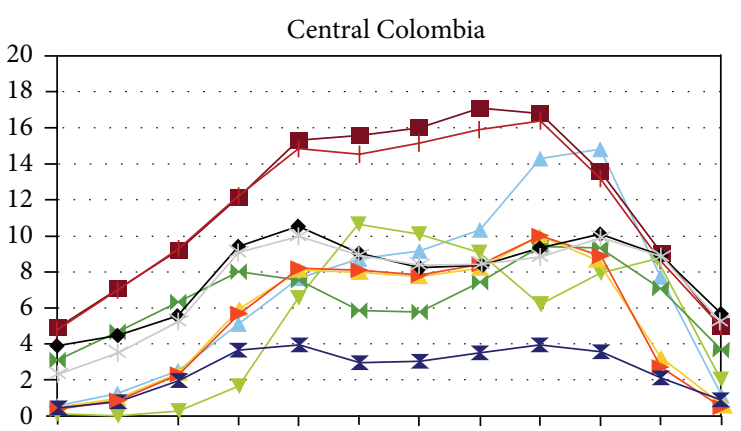

Jan. Feb. Mar. Apr. May. Jun. Jul. Aug. Sep. Oct. Nov. Dec.

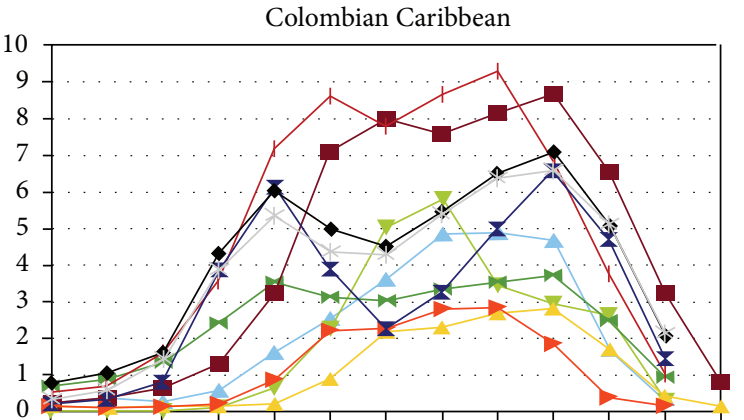

Jan. Feb. Mar. Apr. May. Jun. Jul. Aug. Sep. Oct. Nov. Dec.
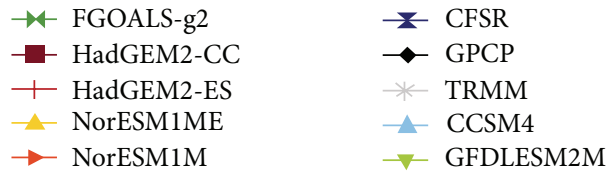

(b)

Figure 6: (a) Map of regions selected to evaluate the simulation of the annual cycle of precipitation by the seven CMIP5 models considered (Amazon region: blue box, Central Colombia region: orange box, Colombian Pacific region: green box, and Colombian Caribbean region: red box); (b) Spatial mean of the rainfall annual cycle in the regions presented in (a). The annual cycle for the Amazon is presented starting in October, in order to visualize the entire wet season over the region. Values for vertical axis are in $\mathrm{mm} / \mathrm{day}$.

over northern South America, since this region is strongly modulated by the SSTs variability over the equatorial Pacific. Possible causes for the observed biases in rainfall simulation over the region of study are explored in the following sections.

\subsection{What Could Cause the Observed Biases in Rainfall Simulation over Northern South America?}

3.5.1. The Simulation of Rainfall and SSTs over the Eastern Pacific and the Interhemispheric SST Gradient. As discussed in Section 1, precipitation over northern South America is strongly modulated by the location of the ITCZ, which in turn is associated with SST and rainfall patterns over the eastern Pacific and Atlantic oceans. Therefore, an adequate simulation of SST and precipitation patterns in the tropical eastern Pacific and Atlantic oceans is important for an adequate simulation of precipitation over northern South America. It has been previously identified that the largest amounts of oceanic rainfall are observed over the areas with highest SSTs, since they supply larger amounts of heat and moisture from the sea surface, triggering convective activity [15]. In the eastern Pacific and eastern Atlantic oceans do not show collocation of minima surface pressure, maxima SST, and convection due 

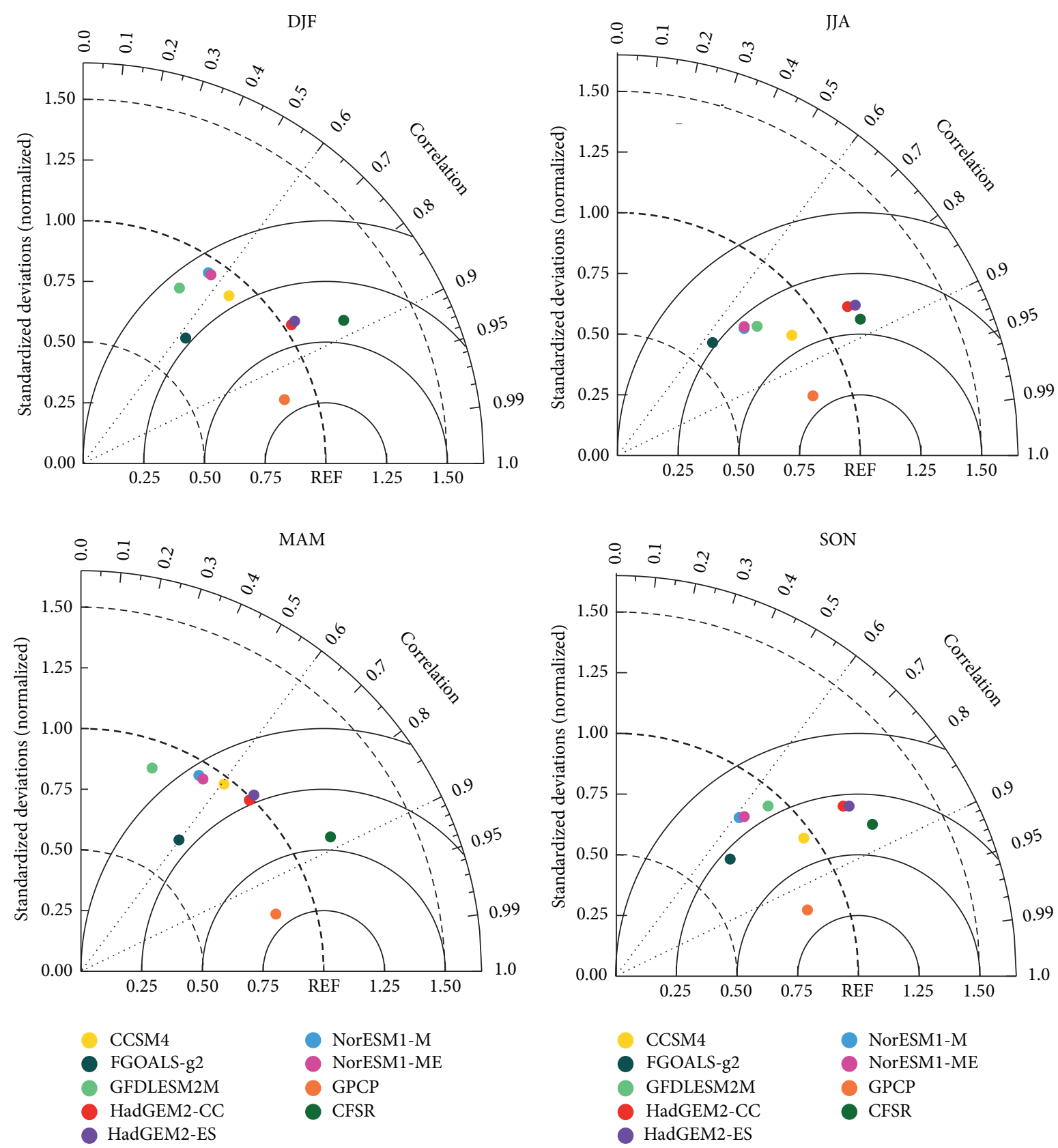

Figure 7: Taylor diagram quantifying the correspondence between the simulated and observed rainfall seasonal climatology for the entire spatial domain $\left(15^{\circ} \mathrm{S}-20^{\circ} \mathrm{N}, 120^{\circ} \mathrm{W}-0^{\circ} \mathrm{W}\right)$. Reference data corresponds to TRMM.

to the strong cross equatorial pressure gradient observed in these regions [52, 53]. In particular, in the eastern Pacific, the convective maxima are located equatorward of the SST maxima. Previous studies show that the distribution of the cross equatorial gradients in pressure and SST determines the location of the off-equatorial convection [52]. Overestimation of SST over a region west of Peru by the coupled models can generate unrealistic simulation of the convection, generating a double ITCZ. Additionally, the alteration of the SST distribution and in turn of the cross equatorial pressure gradient can result in a seasonally migrating ITCZ [52]. Previous analyses of the CMIP5 simulations of precipitation, SST, and other ocean-atmospheric variables in the tropical oceans at intraseasonal and seasonal time scales and their observed biases have focused in the tropical Atlantic region [35]. On the other hand, the CMIP5 simulations of precipitation and SSTs in the tropical Pacific have been studied from a mean state standpoint [15]. The main conclusions from such studies were discussed in Section 3.1. Since the CMIP5 simulations of tropical Atlantic SSTs and precipitation have received more attention in literature than those of the eastern Pacific near the South American coast, we evaluated the relationship between a good representation of the rainfall spatial distribution and a well-simulated SST spatial pattern over the eastern 

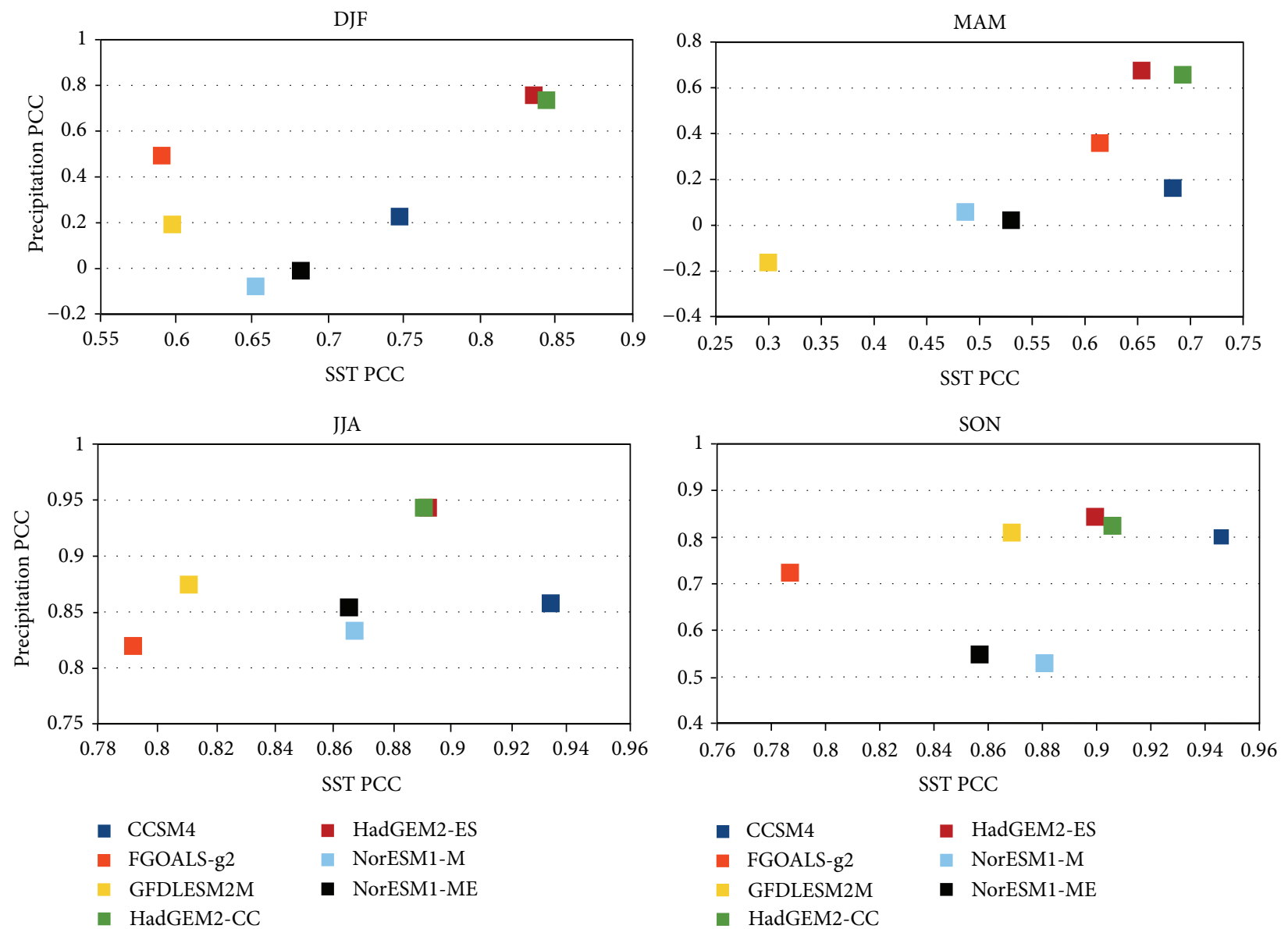

FIGURE 8: Scatter plot of rainfall spatial correlation pattern (respect to TRMM) and SST spatial correlation pattern (with respect to CFSR) for DJF, MAM, JJA, and SON, in the eastern Pacific $\left(15^{\circ} \mathrm{S}-20^{\circ} \mathrm{N}, 120^{\circ} \mathrm{W}-81^{\circ} \mathrm{W}\right)$, as simulated by the seven CMIP5 models selected.

Pacific during the different seasons, in order to identify possible causes for the biases observed in CMIP5 rainfall simulations over northern South America discussed in the previous sections. Figure 8 shows the link between these two features by a scatter plot of SST PCC and precipitation PCC in this region during the four seasons, as obtained from the seven CMIP5 models considered.

Model simulations of the eastern Pacific SSTs and precipitation indicate that, in general, higher values of the SST PCCs are associated with higher rainfall PCCs. Therefore, when the SSTs correlations over the eastern Pacific are higher, the rainfall over this region is best simulated by models, as occurs during JJA and SON (Figures 1 and 8). By contrast, the lowest SST PCCs in the eastern Pacific are observed during MAM, consistent with the lowest rainfall PCCs. In general, the HadGEM2 models reproduce the best spatial patterns of both SST and rainfall over the eastern equatorial Pacific during all the seasons; in addition, CCSM4 and GFDLESM2M also show a good representation in SON (Figure 8). On the contrary, the NorESM1 models show the poorest simulations of both spatial patterns.

To further explore the representation of the eastern Pacific SSTs pattern by the selected models, we computed the interhemispheric SST gradient reproduced by CFSR and
TABLE 2: Seasonal interhemispheric SST gradient over the eastern equatorial Pacific calculated from CFSR and seven CMIP5 models historical runs. Values are in ${ }^{\circ} \mathrm{C}$. Asterisk indicates observational dataset.

\begin{tabular}{lcccc}
\hline Model & DJF & MAM & JJA & SON \\
\hline CFSR $^{*}$ & 1.89517 & 1.49735 & 3.41326 & 3.87762 \\
FGOALS-g2 & 0.45697 & 0.22593 & 1.74464 & 2.12937 \\
GFDLESM2M & 0.503459 & -0.392247 & 2.65928 & 3.71255 \\
HadGEM2-CC & 1.43609 & 0.71975 & 2.55861 & 3.29488 \\
HadGEM2-ES & 1.57853 & 0.860185 & 2.70245 & 3.45589 \\
NorESM1-M & 0.372782 & 0.0790451 & 2.49514 & 2.91459 \\
NorESM1-ME & 0.577846 & 0.181302 & 2.59444 & 3.07089 \\
CCSM4 & 0.396434 & 0.214903 & 2.6481 & 2.93682 \\
\hline
\end{tabular}

model simulations. Figure 9 shows the seasonal zonal average of the climatological SSTs in the tropical eastern Pacific. In addition, Table 2 shows the seasonal interhemispheric SST gradient calculated as the difference between the average of SSTs north $\left(15^{\circ} \mathrm{N}\right.$-equator) and south $\left(15^{\circ} \mathrm{S}\right.$-equator) of equator in the location between $120^{\circ} \mathrm{W}$ and $85^{\circ} \mathrm{W}$.

During all seasons, CFSR displays a strong SST gradient between the northeastern and southeastern equatorial 

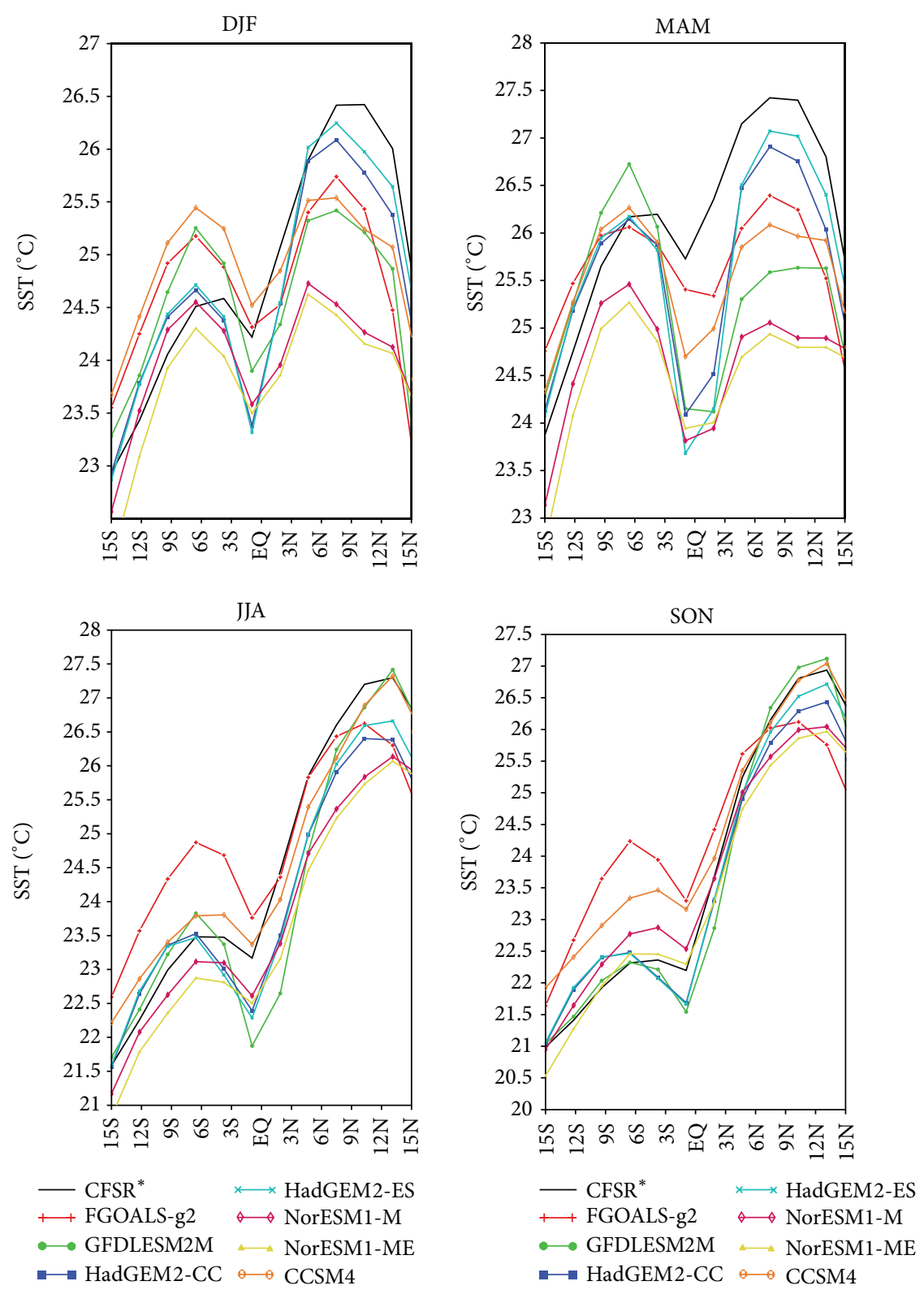

Figure 9: Zonal average of climatological SST for DJF, MAM, JJA, and SON in the eastern equatorial Pacific $\left(15^{\circ} \mathrm{S}-20^{\circ} \mathrm{N}, 120^{\circ} \mathrm{W}-81^{\circ} \mathrm{W}\right)$.

Pacific, with the highest temperatures located north of equator and the lowest south of equator (Figure 9 and Table 2). As expected, the simulated gradients are closer to observations in JJA and SON since the coupled models considered are able to reproduce the warming of the northern tropical Pacific, as discussed in previous sections. In contrast, Figure 9 and Table 2 indicate that models present issues reproducing the interhemispheric temperature gradient during the two first seasons, as also observed in rainfall simulations over this region (Figure 1). However, HadGEM2 models are able to closely reproduce the boreal winter-spring interhemispheric SST gradient over the eastern Pacific (Figure 9 and Table 2), as well as rainfall distribution over the region during these seasons (Figures 1, 7, and 8). By contrast, NorESM1-M simulates the largest bias in interhemispheric temperature gradient during winter and spring seasons. Particularly, CCSM4, along with GFDLESM2M, reproduces similar SST peak magnitudes over the northeastern and southeastern Pacific in DJF, and thus a weak interhemispheric gradient (Table 2). Moreover, GFDLESM2M simulates higher SSTs over the southeastern equatorial Pacific in MAM, producing a negative interhemispheric gradient. FGOALS-g2, although exhibits notably high SSTs located north of the equator in boreal winter (Figure 9), simulates a very low interhemispheric gradient (Table 2) due to its overestimation of SSTs south of the equator.

A comparison between Figures 8 and 9 and Table 2 suggests the relationship between the simulation of the interhemispheric SST gradient and the representation of the spatial patterns of SST and rainfall over the eastern equatorial Pacific. The HadGEM2 models simulate the best interhemispheric gradient as well as the best SST and rainfall patterns over the eastern Pacific. By contrast, NorESM1-M reproduces 
the largest bias in SST gradient during DJF and MAM and one of the lowest rainfall PCCs over the eastern Pacific. In addition, since NorESM1-ME shows a more pronounced interhemispheric SST gradient than NorESM1-M (Table 2), it displays a better representation of the precipitation distribution over the eastern Pacific in DJF (Figures 1 and 8). The negative gradients observed in MAM for GFDLESM2M (Figure 9 and Table 2) could explain that this model exhibits one of the lowest SST PCC and rainfall PCC values, as shown in Figure 8. In boreal spring, only HadGEM2 models and FGOALS-g2 can locate the warmest places north of the equator, exhibiting the best representation of the precipitation spatial pattern in the eastern tropical Pacific (Figure 8).

The biases observed in the simulations of the SST interhemispheric gradient over the eastern Pacific by the selected models are closely related to their ability to realistically simulate the spatial distribution of rainfall over northern South America (Figures 7 and 9 and Table 2). For example, the HadGEM2 models reproduce the best interhemispheric gradient and rainfall pattern over northern South America during the entire year. On the contrary, NorESM1-M, GFDLESM2M, and CCSM4 exhibit the poorest simulations of the interhemispheric gradient, especially in DJF and MAM, and some of the lowest performances simulating rainfall pattern over northern South America. The results discussed here suggest that an adequate simulation of the SST and rainfall patterns over the eastern Pacific, as well as the SST gradient between the northeastern and the southeastern equatorial Pacific, are important for an accurate simulation of the precipitation seasonal pattern over northern South America. However, the causes for the different biases in SST simulations over this ocean need to be further addressed, since they depend not only on forcing factors but also on the intrinsic variability of each particular model.

3.5.2. The Simulation of Local Low-Level Jets. The results discussed above and summarized in Figures 8 and 9 suggest that a key indicator of an adequate representation of rainfall over northern South America appears to be the SST difference between the northeastern and southeastern equatorial Pacific, as well as rainfall distribution over this ocean. This is strongly related with the local ITCZ. However, precipitation over northern South America is not completely determined by the ITCZ location and the associated tropical Atlantic and Pacific SSTs. As identified in previous studies, rainfall seasonality in this region is strongly modulated by local low-level jets, like the Choco jet and the CLLJ, which transport important amounts of moisture to the region $[1,2,7]$. Therefore, another possible cause for the observed biases in the simulated seasonal rainfall patterns over northern South America performed by the seven CMIP5 models selected (Figures 1, 2 , and 7) is the misrepresentation of these local low-level jets. Since the Choco low-level jet, along with its interaction with the CLLJ, is one of the main sources of moisture for northwestern South America, we evaluated how well models simulate these two low-level jets. Figure 10 shows the annual cycle of zonal winds from 1000 to $500 \mathrm{hPa}$ at $82^{\circ} \mathrm{W}$ between $5^{\circ} \mathrm{S}$ and $18^{\circ} \mathrm{N}$. Blank spaces correspond to absent data, due to the topography and/or the horizontal resolution of CMIP5 models.

CFSR zonal wind field is able to represent the annual cycle of the Choco jet described in previous studies, as indicated by westerly winds at $925 \mathrm{hPa}$ (i.e., negative zonal winds) between $5^{\circ} \mathrm{S}$ and $5^{\circ} \mathrm{N}$, with maximum speeds during SON and minimum during MAM (Figure 10(a)). All models are able to reproduce this low-level jet and its annual cycle, although they generally underestimate wind speeds in all seasons. HadGEM2 models show the higher core velocities during JJA instead of SON (Figures 10(d) and 10(e)). NorESM1 models reproduce a much shallower vertical structure of this jet (Figures 10(b) and 10(c)), although they reproduce the observed annual cycle. Finally, FGOALS-g2, CCSM4, and HadGEM2 models (Figures 10(g), 10(h), 10(d), and 10(e), resp.) do not fully represent its vertical structure due to missing data over the region.

To further identify the relationship between monthly grid-point rainfall anomalies and the Choco low-level jet exhibited by observations and model simulations, Figure 11 shows the correspondent correlation coefficients between these two variables over northern South America. Rainfall anomalies were considered in order to avoid biases in the correlations associated with the strong seasonal cycle of precipitation over the region. The low-level jet index was computed as the $925 \mathrm{hPa}$ zonal winds at $82^{\circ} \mathrm{W}$ averaged between $5^{\circ} \mathrm{S}$ and $7^{\circ} \mathrm{N}$, following previous studies [2]. Zonal wind velocities were considered at $82^{\circ} \mathrm{W}$ instead of $80^{\circ} \mathrm{W}$ since several models show no data for $925 \mathrm{hPa}$ zonal winds probably due to boundary continental conditions at this longitude. Hence, a positive index represents a stronger Choco jet whereas a weaker jet occurs during negative index values. Results indicate that CFSR identify positive correlations over western and north Colombia and the easternmost north equatorial Pacific, indicating that a stronger Choco jet is associated with increased precipitation over these regions. By contrast, negative correlations are observed over western Ecuador and the southeastern tropical Pacific, indicating that a stronger Choco jet is associated with reductions of precipitation over the region (Figure 11(a)). This dipole pattern is simulated by the HadGEM2 models and CCSM4 (Figures 11(d), 11(e), and $11(\mathrm{~h})$, resp.), although the negative correlations over western Ecuador and the southeastern Pacific simulated by HadGEM2-CC show a smaller extension. By contrast, the NorESM1 models, GFDL-ESM2M, and FGOALS-g2 exhibit positive correlations over the most of Colombia, Ecuador, Venezuela, and the eastern Pacific (Figures 11(b), 11(c), 11(f), and $11(\mathrm{~g})$, resp.), suggesting that in these models, a stronger Choco jet increases precipitation over the entire region, which differs from what has been previously observed by other studies and shown in Figure 11(a). The better simulation of this low-level jet and its correspondent correlations with rainfall anomalies over northern South America exhibited by the HadGEM2 models and CCSM4, as well as the biased simulations by the GFDL-ESM2M, FGOALS-g2, and NorESM1 models (Figures 10 and 11), are consistent with their performance reproducing the eastern Pacific ITCZ (as shown by both rainfall and SSTs simulations; Figures 1, 2, 8, and 9). However, the dynamics of this jet is associated not only with 

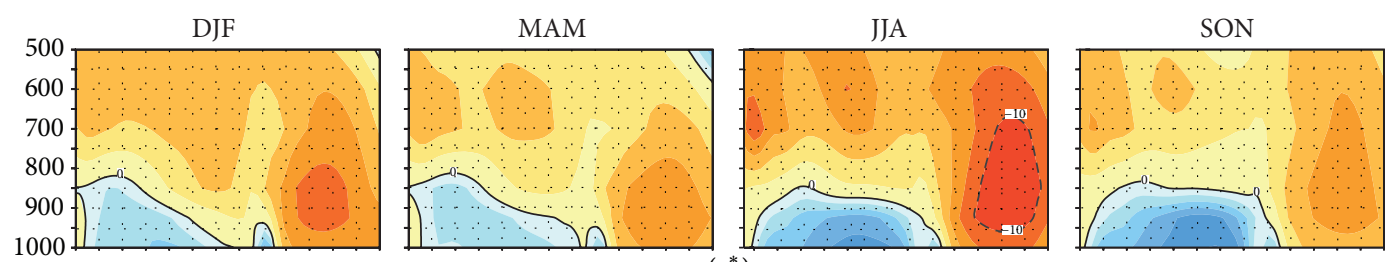

$\left(\mathrm{a}^{*}\right)$
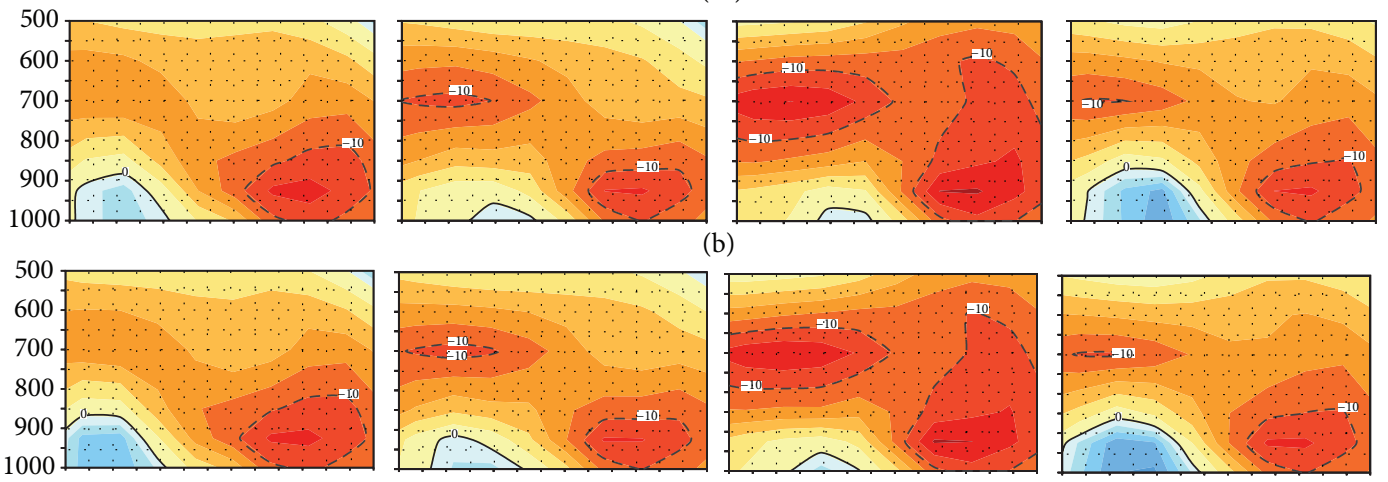

(b)
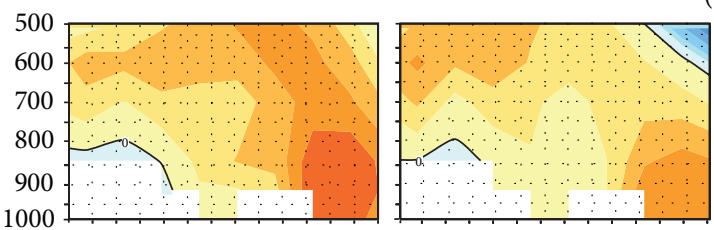

(c)
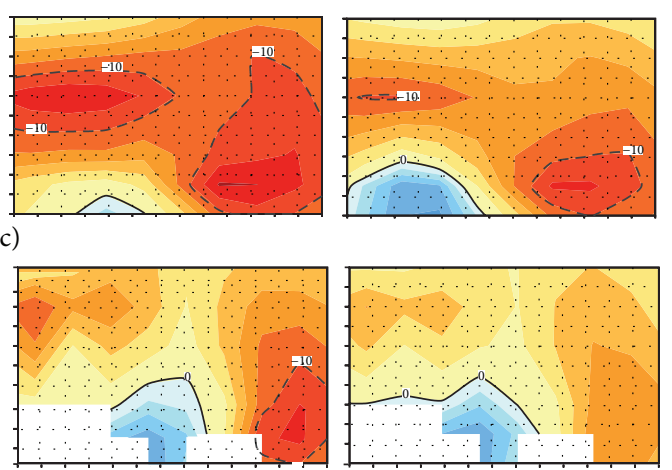

(d)
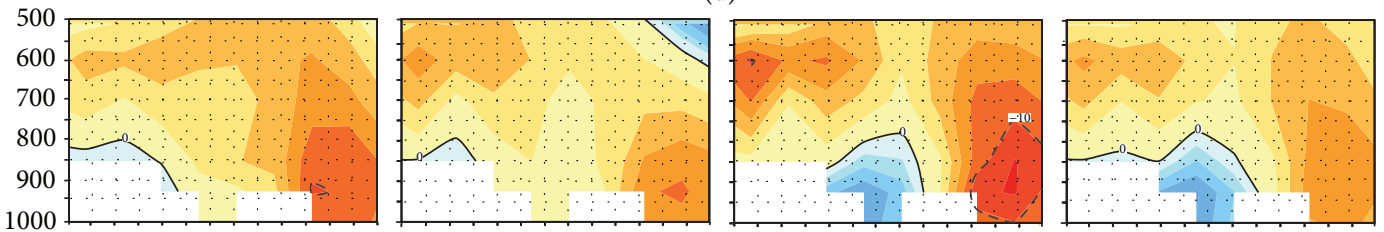

(e)
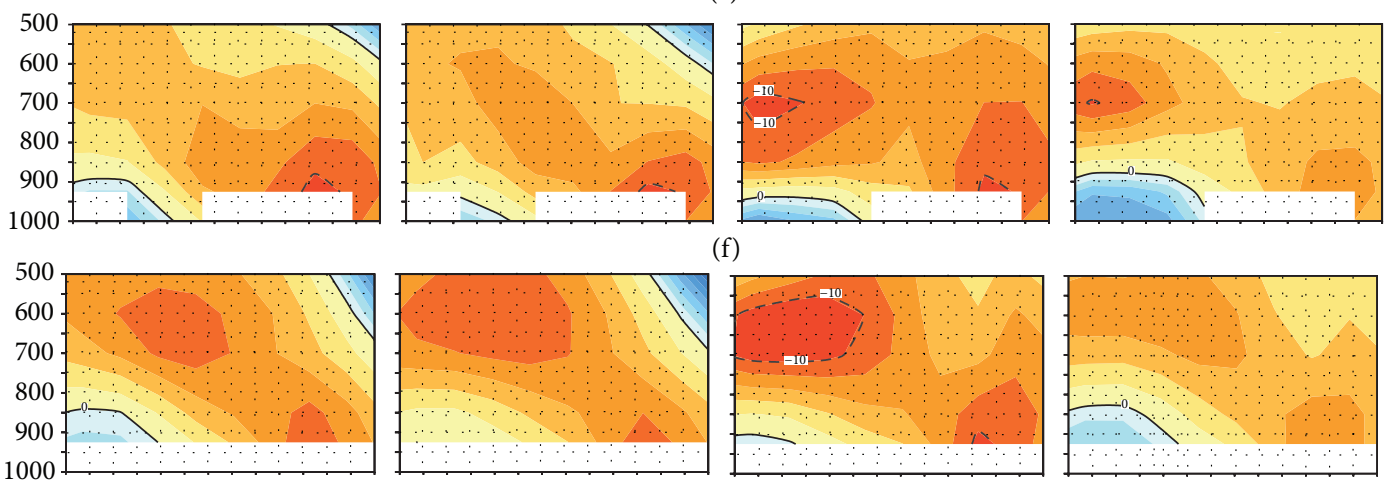

(f)
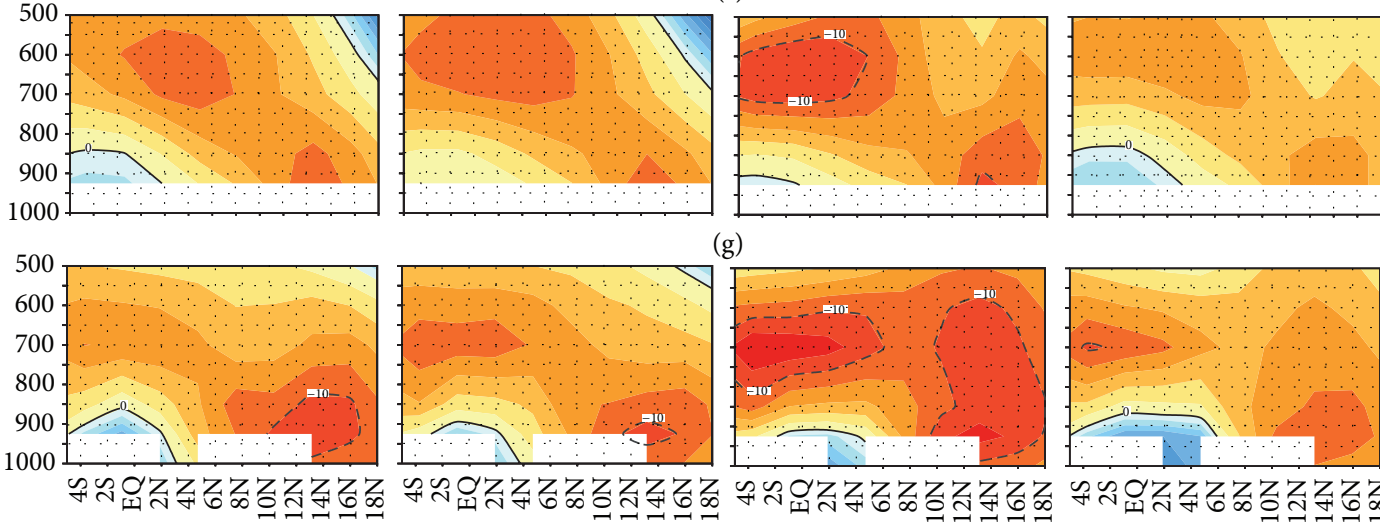

(g)
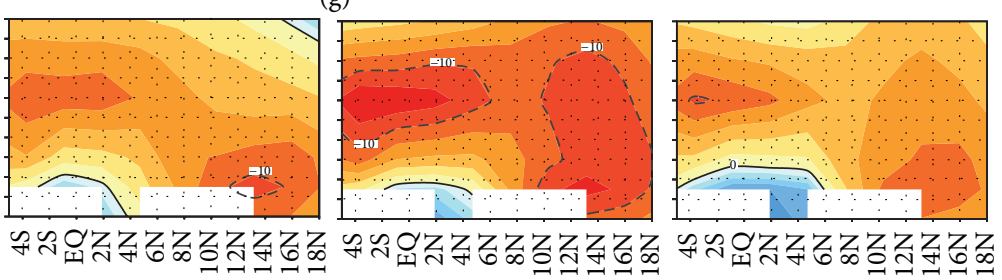

(h)

FIGURE 10: Latitude-height cross sections of the seasonal cycle of the zonal winds at $82^{\circ} \mathrm{W}$ between $5^{\circ} \mathrm{S}$ and $18^{\circ} \mathrm{N}$ ((a) CFSR, (b) NorESM1ME, (c) NorESM1-M, (d) HadGEM2-ES, (e) HadGEM2-CC, (f) GFDLESM2M, (g) FGOALS-g2, and (h) CCSM4). The asterisks indicate the reference datasets. Color bar represents zonal wind speeds in $\mathrm{m} / \mathrm{s}$. 


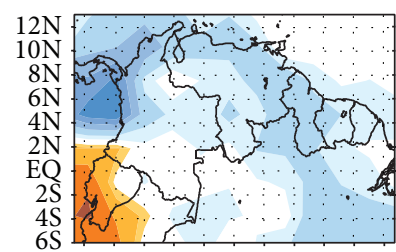

$\left(a^{*}\right)$

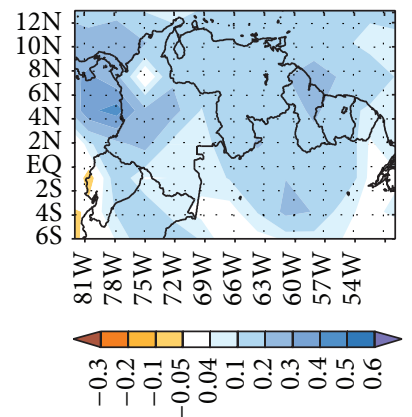

(e)

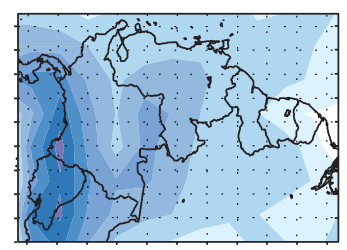

(b)

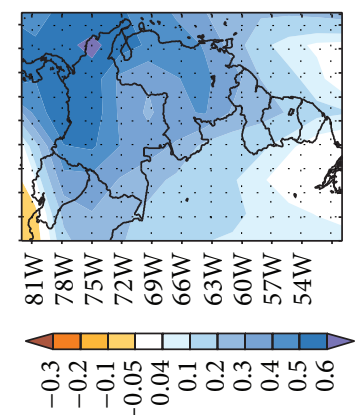

(f)

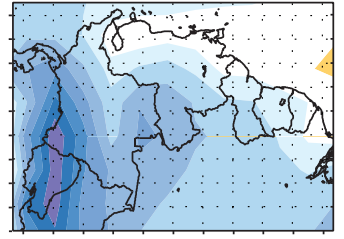

(c)

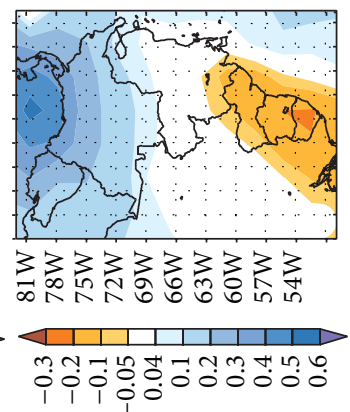

(g)

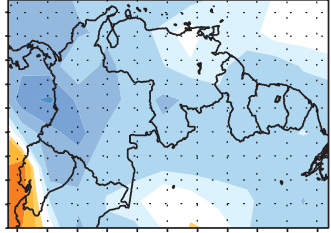

(d)

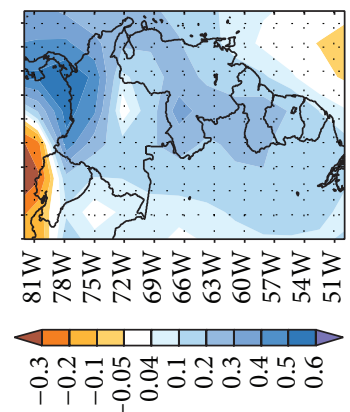

(h)

FIGURE 11: Monthly correlations between Choco jet index and precipitation anomalies over northern South America ((a) CFSR, (b) NorESM1ME, (c) NorESM1-M, (d) HadGEM2-ES, (e) HadGEM2-CC, (f) GFDLESM2M, (g) FGOALS-g2, and (h) CCSM4). The asterisks indicate the reference datasets. Only statistically significant correlations at 0.05 significance level are plotted.

the local ITCZ and related SSTs, but also with local processes [7]. Moreover, the adequate representation of such local phenomenon strongly depends on the horizontal and vertical resolution of the models considered. It must be pointed out that the models with the finest horizontal resolution (CCSM4, HadGEM2-ES, and HadGEM2-CC; see Table 1) exhibit the best representation of the Choco low-level jet and its correlation with rainfall over northern South America.

On the other hand, Figure 10 also shows the observed and simulated Caribbean low-level jet. CFSR observations are able to represent this jet, as indicated by the easterly zonal winds (i.e., negative zonal velocities) centered between $10^{\circ} \mathrm{N}$ and $20^{\circ} \mathrm{N}$ at $1000 \mathrm{hPa}$ to $700 \mathrm{hPa}$. In addition, CFSR exhibit the highest velocities over the Caribbean region in JJA and DJF whereas the lowest velocities are observed during SON and MAM (Figure 10(a)), as identified in previous studies ([4] and references therein). All models are able to simulate and properly locate the core region of this jet. However, only the NorESM1 and HadGEM2 models adequately represent the zonal winds annual cycle over the Caribbean (Figures 10(b) to $10(\mathrm{e})$ ), although the NorESM1 models overestimate the wind speeds in all seasons. In addition, although CCSM4 appropriately simulates the maximum CLLJ core velocities in JJA, it cannot identify the second peak in DJF (Figure 10(h)), while GFDL-ESM2M misrepresents the whole annual cycle of this jet (Figure 10(f)). Finally, the vertical structure of the CLLJ during JJA, when this jet is more intense, is well captured by all the models. In general, our results agree with the conclusions of previous studies of CLLJ simulations in CMIP3 models regarding their ability to represent the CLLJ and its latitudinal location, as well as its vertical structure in JJA [54]; however, these previous studies identify the issues in the CMIP3 models to reproduce the annual cycle of the CLLJ, unlike some or the CMIP5 models analyzed here, as we discussed above.
The results discussed in this section suggest that four of the seven selected CMIP5 models exhibit strong issues simulating the Choco low-level jet; by contrast, all models show a better simulation of the CLLJ. Furthermore, correlation patterns between the Choco jet and precipitation anomalies over northwestern South America indicate that the intensity of this jet is strongly related to local precipitation (Figure 11). Therefore, the biases observed in rainfall simulations over this region could be related with the biases shown by these models when reproducing the Choco low-level jet, as well as the observed biases in simulating the eastern Pacific ITCZ.

\section{Summary and Discussion}

This paper evaluated the simulation of climatological precipitation and its seasonal and interannual variability over northern South America by seven models included in the recently released CMIP5 runs. The seven models were selected based on literature review, considering three main criteria: (i) their representation of the basic features of ENSO (i.e., amplitude and spatial-temporal variability), (ii) their ability to simulate precipitation patterns over the Amazon, and (iii) their representation of rainfall patterns over surrounding oceans and mainland throughout the year. These three aspects were considered since annual and seasonal precipitation over this region is strongly modulated by variability over neighboring oceans, especially ENSO, as well as Amazon convection. Our literature review suggests that NorESM1-M, NorESM1-ME, CCSM4, GFDL-ESM2M, FGOALS-g2, HadGEM2-ES, and HadGEM2-CC are the CMIP5 models that show the best representation of these three features.

The simulations of the seasonal mean precipitation pattern and its interannual variability over northern South America by the seven selected models were compared with satellite (TRMM), reanalysis (CFSR), and reconstructed 
datasets (GPCP). Our results show that the seven models tend to simulate the ITCZ migration over the continent throughout the year, although they disagree on locating the maximum rainfall centers. The HadGEM2 models perform the best representation of the continental rainfall distribution, which is observed consistently during all seasons. However, our results confirm that it is more difficult for models to realistically locate the ITCZ over tropical oceans, especially during DJF and MAM, when the SH is hotter but oceanatmosphere feedbacks locate the ITCZ north of the equator. Consequently, only these models can appropriately reproduce the correct location of the equatorial rainy belt during boreal winter (DJF) and spring (MAM), although they still show the double ITCZ bias in spring. The satisfactory representation of the ITCZ by these models during the two first seasons of the year could be associated with a better simulation of the ocean-atmosphere feedbacks responsible for keeping the ITCZ in this location during these seasons. Conversely, the seven models are able to reproduce oceanic and continental rainfall distribution more easily during boreal summer (JJA) and fall (SON) than for other seasons. This is presumably due to the influence of ocean-atmosphere feedbacks over Atlantic and Pacific oceans, in addition to solar incoming radiation, which locates the ITCZ on the $\mathrm{NH}$. Accordingly, Taylor diagrams display the smallest RMSE and the largest PCC values during JJA and SON, whereas the opposite occurs in DJF and MAM. In addition, our results indicate that the spatial distribution of the standard deviation of precipitation over this region is closely linked to the precipitation pattern, since places with the largest rainfall amplitudes match those displaying the largest standard deviations; hence, a good representation of the spatial distribution and amplitude of the climatological precipitation over the region appears to be a fundamental factor for an adequate representation of its interannual variability.

To verify if models are able to correctly associate rainfall standard deviation patterns over northern South America with the dominant modes of variability over the region and their associated frequencies, we computed the Fast Wavelet Transform of the domain-averaged rainfall in four regions with the largest standard deviations: central tropical Pacific, Amazon, eastern tropical Pacific, and tropical Atlantic. Overall, models are able to identify the dominant modes of rainfall variability in all regions; however, they exhibit issues reproducing the frequency of the main mode of interannual variability over the central equatorial Pacific. Only FGOALSg2 is able to reproduce the observed frequencies associated with ENSO (2-4-year and 4-8-year) in the central equatorial Pacific; by contrast, NorESM1-ME, CCSM4, and GFDLESM2M (CCSM4 and GFDL-ESM2M) show the worse representation of the main frequency mode over the eastern equatorial Pacific (tropical Atlantic). In addition, power spectra of models show the well-known relationship between Amazon rainfall and ENSO variability, reported in previous studies.

To identify if the selected models are able to simulate rainfall seasonal variability over the northern South American continent, we evaluated their representation of the annual cycle of precipitation in four regions with different patterns: Amazon, tropical Andes, Colombian Pacific coast, and
Colombian Caribbean region. In the Amazon region, only HadGEM2 models are able to reproduce the unimodal pattern of the annual cycle of precipitation, exhibiting the closest rainfall amplitudes to observations, while other models exhibit a bimodal rainfall pattern and underestimate its amplitude during almost the entire year (especially GFDLESM2M in SON). In the other regions, the models that cannot adequately reproduce the location of the ITCZ during DJF and MAM (i.e., CCSM4, NorESM1-ME, NorESM1-M, and GFDL-ESM2M) considerably underestimate rainfall during the same months in these regions. This suggests that a good representation of the ITCZ over the tropical Pacific is related to a better representation of the annual cycle of precipitation over northern South America.

What causes the biases observed in seasonal rainfall simulations by the seven selected CMIP5 models? Several studies have highlighted the strong influence of tropical Atlantic and Pacific SST variability on precipitation over northern South America. Evaluation of the simulation of Atlantic SSTs by CMIP models has been addressed in other studies. Here, we evaluated the representation of SSTs and rainfall in the eastern tropical Pacific by the selected models, as well as their simulated interhemispheric SST gradient over this ocean. Results indicate that, in general, a better representation of the eastern tropical Pacific SSTs pattern by the models (i.e., higher PCCs) is associated with a better representation of rainfall over the region (i.e., higher rainfall PCCs). Furthermore, our results suggest that a key indicator of an adequate rainfall representation in the eastern tropical Pacific seems to be the difference between temperature peaks in both northeastern and southeastern tropical Pacific (i.e., the interhemispheric SST gradient). Hence, models with a better simulation of the interhemispheric temperature gradient in the eastern tropical Pacific (HadGEM2 models) can reproduce a better spatial pattern of both SST and rainfall over this ocean.

Another source of influence for seasonal precipitation over northern South America corresponds to the local lowlevel jets in the region, such as the Choco and Caribbean jets. Therefore, to further address the question above, we explored the ability of the seven CMIP5 models selected to simulate such local phenomena. Results indicate that FGOALS-g2 and HadGEM2 models are able to reproduce the Choco jet and its annual cycle whereas the CCSM4, GFDL-ESM2M, and NorESM1 models do not reproduce the shallow and nearsurface vertical structure of this jet, as well as its intensity. On the other hand, most models identify the Caribbean jet. Only few models simulate its seasonal cycle (NorESM1-M, NorESM1-ME, HadGEM2-CC, and HadGEM2-ES) whereas CCSM4 and FGOALS-g2 cannot reproduce the second peak of zonal winds in DJF. In addition, results indicate that only HadGEM2 models and CCSM4 realistically represent the observed dipole relationship between rainfall in northwestern Colombia/north equatorial Pacific and that in western Ecuador/southern equatorial Pacific, related to the Choco jet. By contrast, FGOALS-g2, GFDL-ESM2M, and NorESM1 models exhibit a poor simulation of this pattern.

The results presented in this paper suggest that the biases observed in rainfall simulations over northern South America appear to be related to the biases shown by the selected 
CMIP5 models when reproducing the eastern Pacific ITCZ and the local low-level jets, especially the Choco jet. Although the eastern Pacific SSTs are an important factor involved in the dynamics of the Choco jet, as evidenced by the strong ENSO influence on the interannual variability of this lowlevel jet [1], this dynamics also relies on highly local processes such as orographic lifting over the western tropical Andes slopes, land surface conditions over northwestern South America, and vegetation feedbacks in the Darien forest [7], as well as strongly depends on the horizontal and vertical resolution of the models considered. Furthermore, recent studies have explored the role of local vegetation on preferential atmospheric pathways for moisture transport to northern South America, such as the Choco low-level jet [7]. Therefore, a more detailed spatial resolution and a better inclusion of land surface and vegetation processes over northern South America in the current CMIP5 models are necessary to improve their ability to simulate this low-level jet, and consequently, improve their simulation of the seasonal precipitation over northern South America. On the other hand, previous studies have evaluated the simulations of the CLLJ by CMIP3 models [53]; however, to our knowledge, the evaluation of the Choco jet by GCMs has not been widely addressed. Hence, the results presented here contribute to the evaluation of simulations of the seasonal precipitation over northern South America by the CMIP5 models, with focus on the local processes represented by the Choco jet. These results are a first exploration of the possible causes for the biases observed in the selected CMIP5 models simulations of the seasonal precipitation over northern South America and its interannual variability. A more detailed analysis of the different factors and mechanisms involved in these biases as well as a careful identification of the different particularities of the CMIP5 models related to such biases needs to be further addressed.

In summary, our results suggest that the models with a better representation of the oceanic ITCZ and the local lowlevel jets over northern South America (HadGEM2 models) are able to simulate the main features of seasonal precipitation variability over northern South America, which is a necessary condition in order to analyze their projections under a climate change scenario for this region. The latter is urgently required since northern South America has been recognized as one of the most vulnerable regions to be affected by climate change [17]. Therefore, the evaluation of climate change projections and its possible impacts on this region are a necessary path in order to formulate assertive adaptation and mitigation strategies in the region.

\section{Conflict of Interests}

The authors declare that there is no conflict of interests regarding the publication of this paper.

\section{Acknowledgments}

This work was supported by "Departamento Administrativo de Ciencia, Tecnología e Innovación de Colombia” (Colciencias) Program no. 5509-543-31966. The authors acknowledge the World Climate Research Programme's Working Group on Coupled Modelling, which is responsible for CMIP, and they also thank the climate modeling groups (listed in Table 1 of this paper) for producing and making available their model output. For CMIP, the US Department of Energy's Program for Climate Model Diagnosis and Intercomparison provided coordinating support and led development of software infrastructure in partnership with the Global Organization for Earth System Science Portals. The authors also acknowledge the insightful comments from two anonymous reviewers, which helped to improve this paper.

\section{References}

[1] G. Poveda, P. R. Waylen, and R. S. Pulwarty, "Annual and interannual variability of the present climate in northern South America and southern Mesoamerica," Palaeogeography, Palaeoclimatology, Palaeoecology, vol. 234, no. 1, pp. 3-27, 2006.

[2] G. Poveda and O. J. Mesa, "On the existence of Lloró (the rainiest locality on earth): enhanced ocean-land-atmosphere interaction by a low-level jet," Geophysical Research Letters, vol. 27, no. 11, pp. 1675-1678, 2000.

[3] K. H. Cook and E. K. Vizy, "Hydrodynamics of the Caribbean low-level jet and its relationship to precipitation," Journal of Climate, vol. 23, no. 6, pp. 1477-1494, 2010.

[4] S. Hastenrath, "Equatorial mid-tropospheric Easterly jet over the Eastern Pacific," Journal of the Meteorological Society of Japan, vol. 77, no. 3, pp. 701-709, 1999.

[5] R. A. Maddox, "Mesoscale convective complexes (USA)," Bulletin, American Meteorological Society, vol. 61, pp. 1374-1387, 1980.

[6] L. Gimeno, A. Stohl, R. M. Trigo et al., "Oceanic and terrestrial sources of continental precipitation," Reviews of Geophysics, vol. 50, no. 4, Article ID RG4003, 2012.

[7] G. Poveda, L. Jaramillo, and L. F. Vallejo, "Seasonal precipitation patterns along pathways of South American low-level jets and aerial rivers," Water Resources Research, vol. 50, no. 1, pp. 98-118, 2014.

[8] D. V. Spracklen, S. R. Arnold, and C. M. Taylor, "Observations of increased tropical rainfall preceded by air passage over forests," Nature, vol. 489, no. 7415, pp. 282-285, 2012.

[9] G. Poveda, O. J. Mesa, L. F. Salazar et al., "The diurnal cycle of precipitation in the tropical Andes of Colombia," Monthly Weather Review, vol. 133, no. 1, pp. 228-240, 2005.

[10] J. A. Foley, "El Niño-Southern oscillation and the climate, ecosystems and rivers of Amazonia," Global Biodeochemical Cycles, vol. 16, no. 4, pp. 79-1-79-20, 2002.

[11] R. Fu, R. E. Dickinson, M. Chen, and H. Wang, "How do tropical sea surface temperatures influence the seasonal distribution of precipitation in the equatorial Amazon?" Journal of Climate, vol. 14, no. 20, pp. 4003-4026, 2001.

[12] A. M. Grimm, "Interannual climate variability in South America: impacts on seasonal precipitation, extreme events, and possible effects of climate change," Stochastic Environmental Research and Risk Assessment, vol. 25, no. 4, pp. 537-554, 2011.

[13] G. A. M. da Silva, A. Drumond, and T. Ambrizzi, "The impact of El Niño on South American summer climate during different phases of the Pacific Decadal Oscillation," Theoretical and Applied Climatology, vol. 106, no. 3-4, pp. 307-319, 2011.

[14] G. Flato, J. Marotzke, B. Abiodun et al., "Evaluation of climate models," in Climate Change 2013: The Physical Science Basis. 
Contribution of Working Group I to the Fifth Assessment Report of the Intergovernmental Panel on Climate Change, T. F. Stocker, D. Qin, G.-K. Plattner et al., Eds., Cambridge University Press, Cambridge, UK, 2014.

[15] N. Hirota and Y. N. Takayabu, "Reproducibility of precipitation distribution over the tropical oceans in CMIP5 multi-climate models compared to CMIP3," Climate Dynamics, vol. 41, no. 1112, pp. 2909-2920, 2013.

[16] L. Yin, R. Fu, E. Shevliakova, and R. E. Dickinson, "How well can CMIP5 simulate precipitation and its controlling processes over tropical South America?" Climate Dynamics, vol. 41, no. 11-12, pp. 3127-3143, 2013.

[17] G. Magrin, J. Marengo, J.-P. Boulanger et al., "Regional aspects: central and south America," in Climate Change 2014: Impacts, Adaptation, and Vulnerability, Contribution of Working Group II to the Fifth Assessment Report of the Intergovernmental Panel on Climate Change, vol. 2, 2014.

[18] N. Hoyos, J. Escobar, J. C. Restrepo, A. M. Arango, and J. C. Ortiz, "Impact of the 2010-2011 La Niña phenomenon in Colombia, South America: the human toll of an extreme weather event," Applied Geography, vol. 39, pp. 16-25, 2013.

[19] F. J. Tapiador, F. J. Turk, W. Petersen et al., "Global precipitation measurement: methods, datasets and applications," Atmospheric Research, vol. 104-105, pp. 70-97, 2012.

[20] G. J. Huffman, R. F. Adler, D. T. Bolvin et al., "The TRMM multisatellite precipitation analysis (TMPA): quasi-global, multiyear, combined-sensor precipitation estimates at fine scales," Journal of Hydrometeorology, vol. 8, no. 1, pp. 38-55, 2007.

[21] R. F. Adler, G. J. Huffman, A. Chang et al., “The version-2 global precipitation climatology projec (GPCP) monthly precipitation analysis (1979-present)," Journal of Hydrometeorology, vol. 4, no. 6, pp. 1147-1167, 2003.

[22] R. I. Negrón Juárez, W. Li, R. Fu, K. Fernandes, and A. de Oliveira Cardoso, "Comparison of precipitation datasets over the tropical South American and African continents," Journal of Hydrometeorology, vol. 10, no. 1, pp. 289-299, 2009.

[23] S. Saha, S. Moorthi, H.-L. Pan et al., "The NCEP climate forecast system reanalysis," Bulletin of the American Meteorological Society, vol. 91, no. 8, pp. 1015-1057, 2010.

[24] J. Wang, W. Wang, X. Fu, and K. H. Seo, “Tropical intraseasonal rainfall variability in the CFSR," Climate Dynamics, vol. 38, no. 11-12, pp. 2191-2207, 2012.

[25] A. Kumar and Z.-Z. Hu, "Uncertainty in the ocean-atmosphere feedbacks associated with ENSO in the reanalysis products," Climate Dynamics, vol. 39, no. 3, pp. 575-588, 2012.

[26] K. E. Taylor, R. J. Stouffer, and G. A. Meehl, "An overview of CMIP5 and the experiment design," Bulletin of the American Meteorological Society, vol. 93, no. 4, pp. 485-498, 2012.

[27] K. E. Taylor, "Summarizing multiple aspects of model performance in a single diagram," Journal of Geophysical Research D: Atmospheres, vol. 106, no. 7, pp. 7183-7192, 2001.

[28] J.-Y. Lee and B. Wang, "Future change of global monsoon in the CMIP5," Climate Dynamics, vol. 42, no. 1-2, pp. 101-119, 2014.

[29] H. Bellenger, E. Guilyardi, J. Leloup, M. Lengaigne, and J. Vialard, "ENSO representation in climate models: from CMIP3 to CMIP5," Climate Dynamics, vol. 42, no. 7-8, pp. 1999-2018, 2014.

[30] J.-S. Kug, Y.-G. Ham, J.-Y. Lee, and F.-F. Jin, "Improved simulation of two types of El Niño in CMIP5 models," Environmental Research Letters, vol. 7, no. 3, Article ID 034002, 2012.
[31] B. Jha, Z.-Z. Hu, and A. Kumar, "SST and ENSO variability and change simulated in historical experiments of CMIP5 models," Climate Dynamics, vol. 42, no. 7-8, pp. 2113-2124, 2014.

[32] J.-P. Michael, V. Misra, and E. P. Chassignet, “The El Niño and Southern Oscillation in the historical centennial integrations of the new generation of climate models," Regional Environmental Change, vol. 13, no. 1, pp. 121-130, 2013.

[33] Y. Yu, J. He, W. Zheng, and Y. Luan, "Annual cycle and interannual variability in the tropical pacific as simulated by three versions of FGOALS," Advances in Atmospheric Sciences, vol. 30, no. 3, pp. 621-637, 2013.

[34] S. T. Kim and J.-Y. Yu, "The two types of ENSO in CMIP5 models," Geophysical Research Letters, vol. 39, no. 11, Article ID L11704, 2012.

[35] I. Richter, S.-P. Xie, S. K. Behera, T. Doi, and Y. Masumoto, "Equatorial Atlantic variability and its relation to mean state biases in CMIP5," Climate Dynamics, vol. 42, no. 1-2, pp. 171188, 2014.

[36] C. Torrence and G. P. Compo, "A practical guide to wavelet analysis," Bulletin of the American Meteorological Society, vol. 79, no. 1, pp. 61-78, 1998.

[37] T. Li and S. G. H. Philander, "On the annual cycle of the eastern equatorial Pacific," Journal of Climate, vol. 9, no. 12, pp. 29862998, 1996.

[38] S. P. de Szoeke and S.-P. Xie, "The tropical eastern pacific seasonal cycle: assessment of errors and mechanisms in IPCC AR4 coupled ocean-atmosphere general circulation models," Journal of Climate, vol. 21, no. 11, pp. 2573-2590, 2008.

[39] S. P. Xie and S. G. H. Philander, "A coupled ocean-atmosphere model of relevance to the ITCZ in the eastern Pacific," Tellus A, vol. 46, no. 4, pp. 340-350, 1994.

[40] I. Richter, S.-P. Xie, A. T. Wittenberg, and Y. Masumoto, "Tropical Atlantic biases and their relation to surface wind stress and terrestrial precipitation," Climate Dynamics, vol. 38, no. 5-6, pp. 985-1001, 2012.

[41] E. M. Rasmusson and T. H. Carpenter, "Variations in tropical sea surface temperature and surface wind fields associated with the Southern Oscillation/El Niño," Monthly Weather Review, vol. 110, no. 5, pp. 354-384, 1982.

[42] C. Wang and P. C. Fiedler, "ENSO variability and the eastern tropical Pacific: a review," Progress in Oceanography, vol. 69, no. 2-4, pp. 239-266, 2006.

[43] C. B. Uvo, C. A. Repelli, S. E. Zebiak, and Y. Kushnir, "The relationships between tropical Pacific and Atlantic SST and northeast Brazil monthly precipitation," Journal of Climate, vol. 11, no. 4, pp. 551-562, 1998.

[44] S.-P. Xie and J. A. Carton, "Tropical atlantic variability: patterns, mechanisms, and impacts," in Earth's Climate, 2004.

[45] IDEAM, Atlas Climatológico de Colombia, IDEAM, Bogotá, Colombia, 1st edition, 2005.

[46] P. R. Gent, G. Danabasoglu, L. J. Donner et al., "The community climate system model version 4," Journal of Climate, vol. 24, no. 19, pp. 4973-4991, 2011.

[47] L. J. Li, P. Lin, Y. Yu et al., "The flexible global ocean-atmosphere-land system model, grid-point version 2: FGOALS-g2," Advances in Atmospheric Sciences, vol. 30, no. 3, pp. 543-560, 2013.

[48] J. P. Dunne, J. G. John, A. J. Adcroft et al., "GFDL’s ESM2 global coupled climate-carbon earth system models. Part I: physical formulation and baseline simulation characteristics," Journal of Climate, vol. 25, no. 19, pp. 6646-6665, 2012. 
[49] W. J. Collins, N. Bellouin, M. Doutriaux-Boucher et al., "Development and evaluation of an Earthsystem model-HadGEM2," Geoscientific Model Development, vol. 4, no. 2, pp. 997-1062, 2011.

[50] C. D. Jones, J. K. Hughes, N. Bellouin et al., "The HadGEM2ES implementation of CMIP5 centennial simulations," Geoscientific Model Development, vol. 4, no. 3, pp. 543-570, 2011.

[51] M. Bentsen, I. Bethke, J. B. Debernard et al., "The Norwegian Earth System Model, NorESM1-M-Part 1: Description and basic evaluation of the physical climate," Geoscientific Model Development, vol. 6, no. 3, pp. 687-720, 2013.

[52] R. A. Tomas and P. J. Webster, "The role of inertial instability in determining the location and strength of near-equatorial convection," Quarterly Journal of the Royal Meteorological Society, vol. 123, no. 542, pp. 1445-1482, 1997.

[53] S. G. H. Philander, D. Gu, D. Halpern et al., "Why the ITCZ is mostly north of the equator," Journal of Climate, vol. 9, no. 12, pp. 2958-2972, 1996.

[54] E. R. Martin and C. Schumacher, "The caribbean low-level jet and its relationship with precipitation in IPCC AR4 models," Journal of Climate, vol. 24, no. 22, pp. 5935-5950, 2011. 

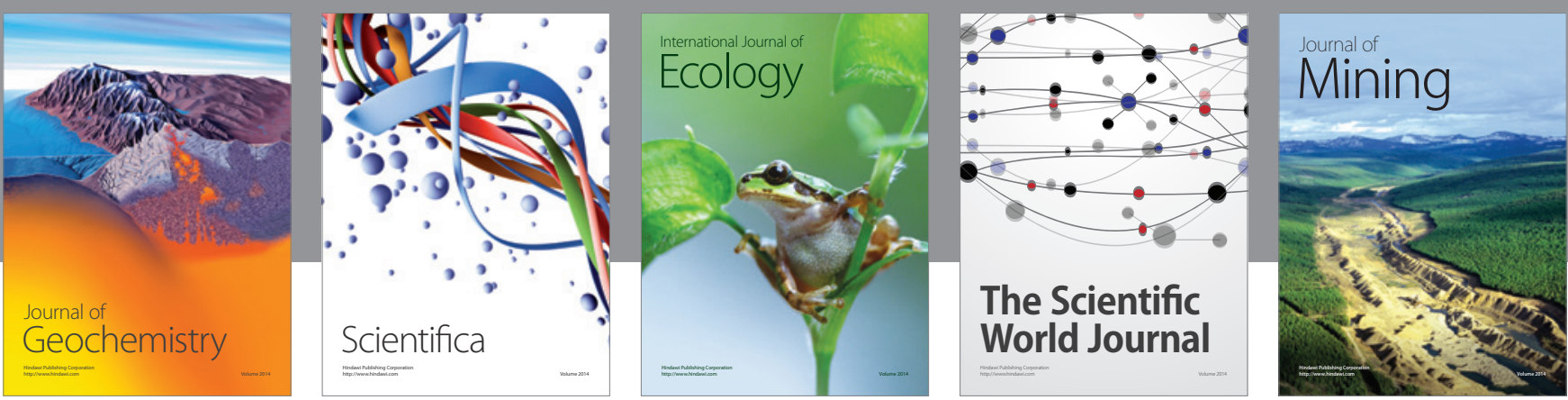

The Scientific World Journal
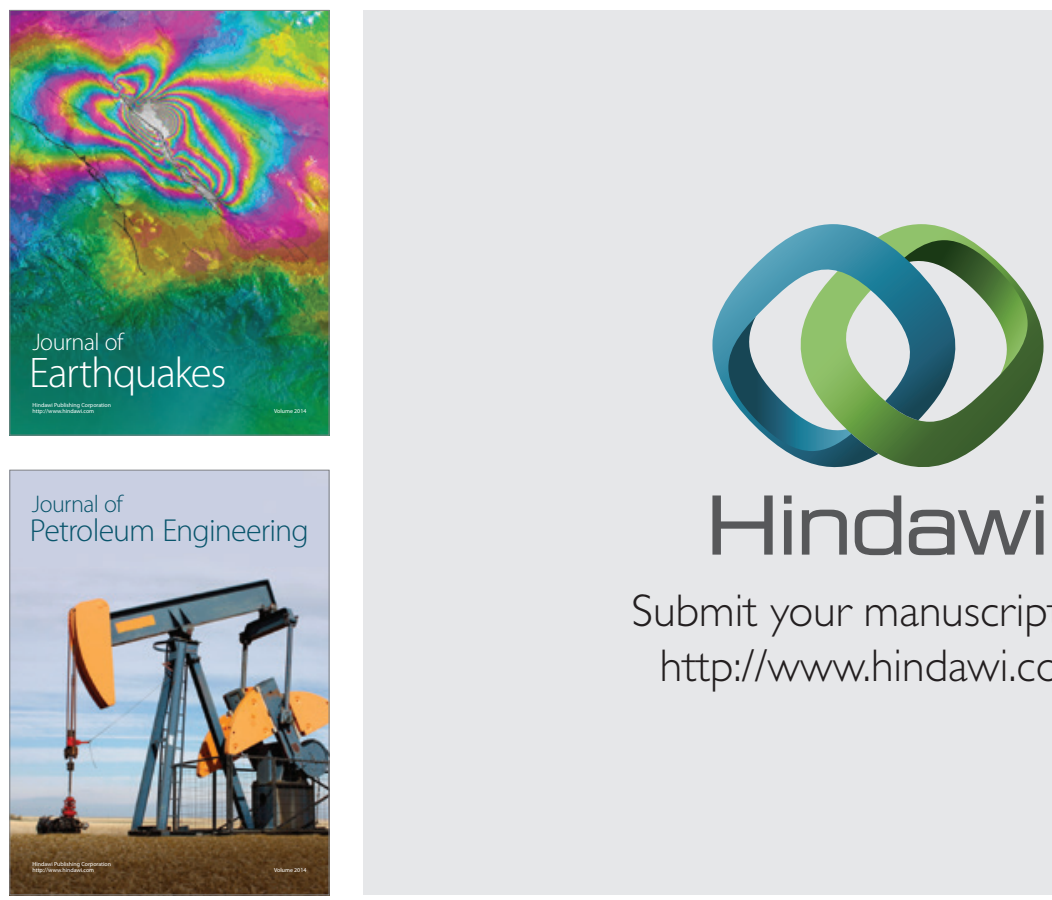

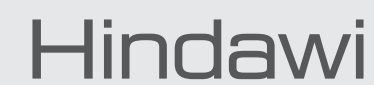

Submit your manuscripts at

http://www.hindawi.com
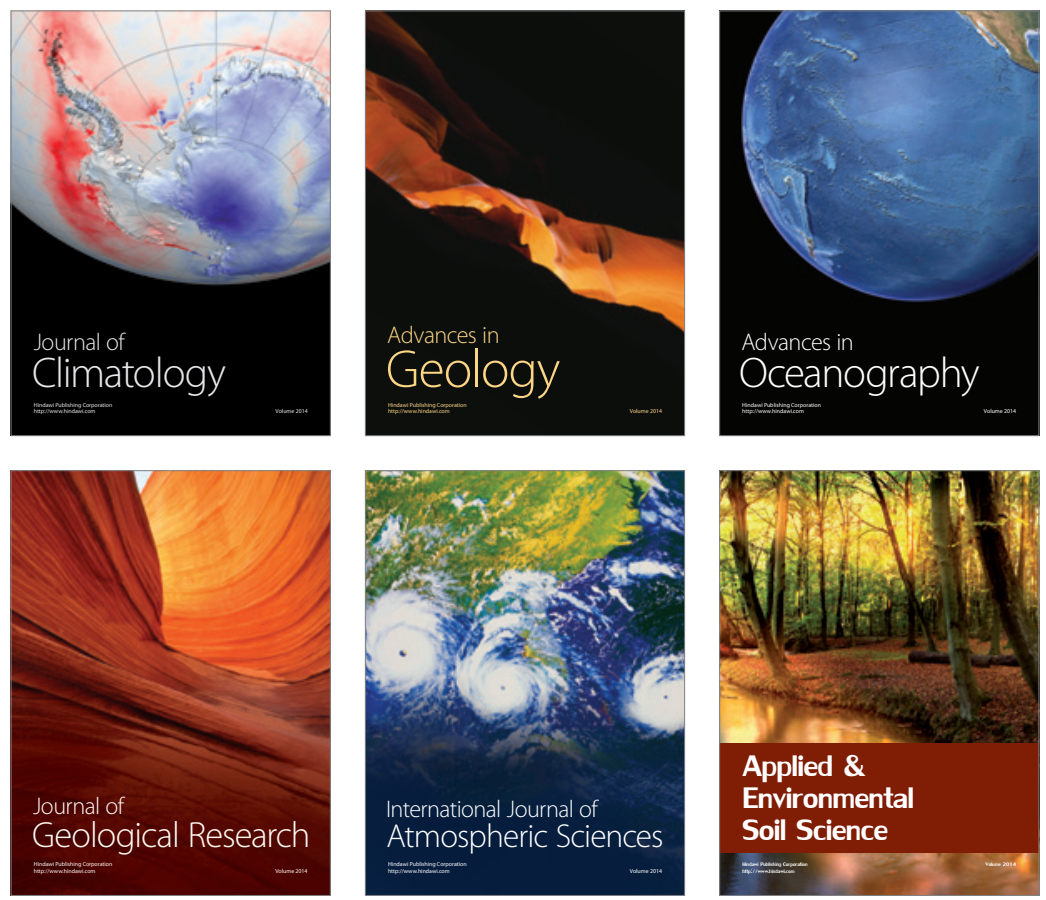
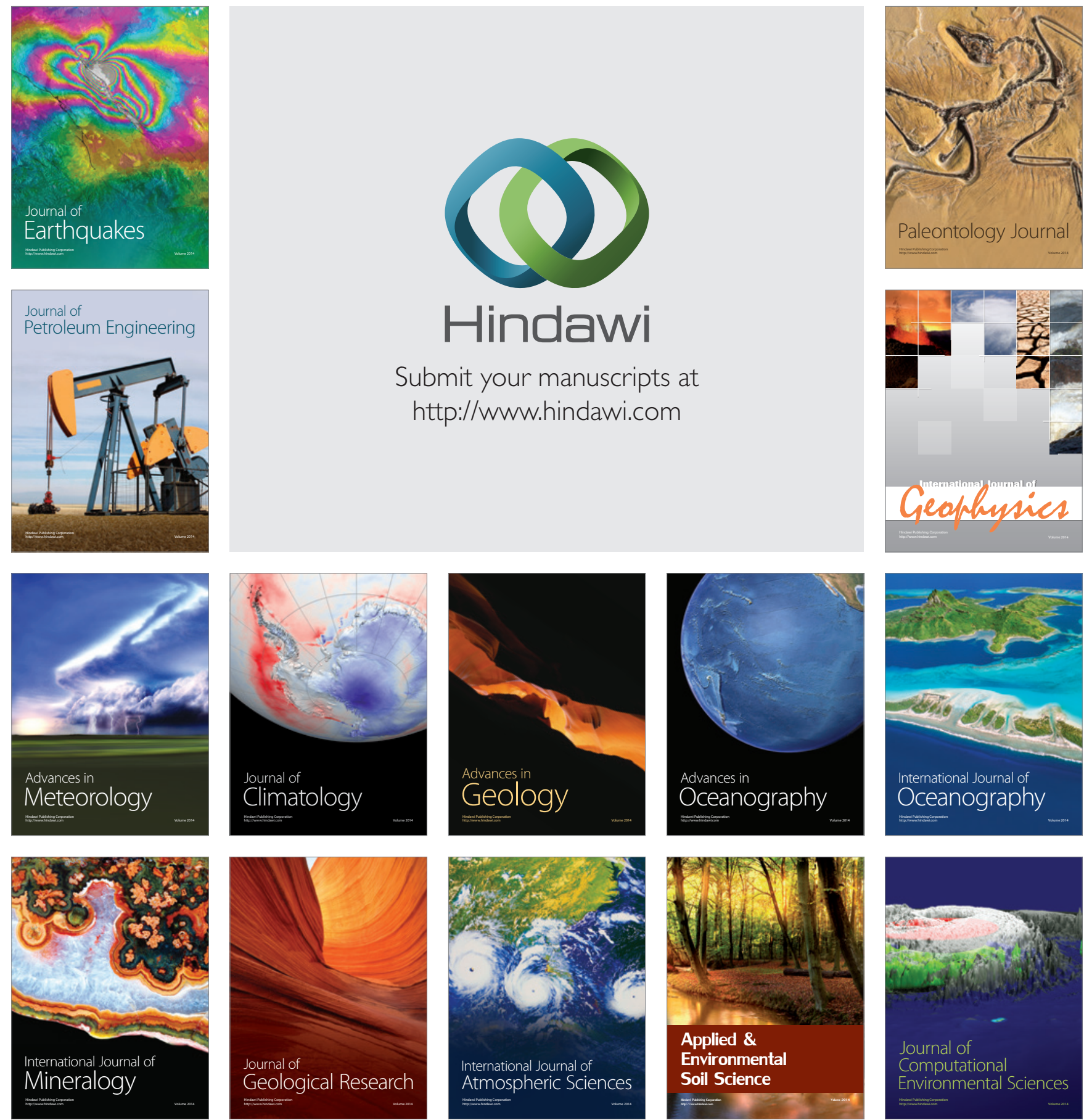